\title{
The Display Makes a Difference: A Mobile Eye Tracking Study on the Perception of Art Before and After a Museum's Rearrangement
}

Luise Reitstätter, ${ }^{1,4}$

$$
\text { Thiago Santini, }{ }^{2}
$$$$
\text { Zoya Dare, }{ }^{1,4}
$$

Anna Miscená, ${ }^{1,4}$

Helmut Leder, 3, 4

\author{
Hanna Brinkmann, 1, 4
}

Eva Specker, 3,4

Flora Bakondi, ${ }^{1,4}$

Enkelejda Kasneci, ${ }^{2}$

Raphael Rosenberg ${ }^{1,4,5}$

${ }^{1}$ Department of Art History, University of Vienna, Austria

${ }^{2}$ Department of Computer Science, University of Tübingen, Germany

${ }^{3}$ Faculty of Psychology, University of Vienna, Austria

${ }^{4}$ Vienna Cognitive Science Hub, University of Vienna, Austria

${ }^{5}$ MECS, Leuphana University Lüneburg, Germany

\begin{abstract}
There is increasing awareness that the perception of art is affected by the way it is presented. In 2018, the Austrian Gallery Belvedere redisplayed its permanent collection. Our multidisciplinary team seized this opportunity to investigate the viewing behavior of specific artworks both before and after the museum's rearrangement. In contrast to previous mobile eye tracking (MET) studies in museums, this study benefits from the comparison of two realistic display conditions (without any research interference), an unconstrained study design (working with regular museum visitors), and a large data sample (comprising 259 participants). We employed a mixed-method approach that combined mobile eye tracking, subjective mapping (a drawing task in conjunction with an open interview), and a questionnaire in order to relate gaze patterns to processes of meaning-making. Our results show that the new display made a difference in that it 1) generally increased the viewing times of the artworks; 2) clearly extended the reading times of labels; and 3) deepened visitors' engagement with the artworks in their exhibition reflections. In contrast, interest in specific artworks and art form preferences proved to be robust and independent of presentation modes.
\end{abstract}

Keywords: mobile eye tracking, usability, museum studies, art perception, visitor research, exhibition display, attention, social influences

Received April 8, 2020; Published June 19, 2020.

Citation: Reitstätter, L., Brinkmann, H, Santini T., Specker, E., Dare Z., Bakondi, F., Miscená, A., Kasneci, E., Leder, H., Rosenberg, R. (2020). The display makes a difference: A mobile eye tracking study on the perception of art before and after a museum's rearrangement. Journal of Eye Movement Research, 13(2):6.

Digital Object Identifier: 10.16910/jemr.13.2.6

ISSN: $1995-8692$

This article is licensed under a Creative Commons Attribution 4.0 International license. (c) EY EY

\section{Introduction}

Since the $18^{\text {th }}$ century, with the birth of the public museum, the way art is presented has been crucial to discussions about its perception (Bennett, 1995; Müller \& Möhlmann, 2014; Noordegraaf, 2004; Staniszewski, 1998; Ward, 1991). Today, the umbrella term "display" encompasses the visual, material, and social aspects of art presentations (Beck, 2016; Hughes, 2015; Macdonald, 2007; 
MacLeod et al., 2018). The idea that not only the "what" but also the "how" of an exhibition provides meaning has become a commonplace of contemporary museum and curatorial studies. This new emphasis is also pivotal to research on art perception, as Pelowski, Forster et al. (2017) state: "Factors related to the presentational context may mark the most overlooked and potentially most fruitful area for future research on the psychology of art." But how substantial is the influence of display on our museum experience? And to what extent does display really matter with respect to different viewing patterns? To answer these questions, studies on art perception need to transfer their site of research from the laboratory to the museum itself.

In the art museum, the visual sense is leading: We walk from painting to painting and around sculptures, read textual information, and negotiate our paths in order to set our gaze in place. The gaze, which can be registered with eye tracking, is the bridge between the artworks and us. Soon after the first eye tracking devices were built, artworks were used as stimuli-but by psychologists, not by art historians (Buswell, 1935; Yarbus, 1967). More recently, the experimental investigation of eye movements was introduced to art history (Rosenberg \& Klein, 2015). Several studies have used eye trackers to analyze the perception of single artworks (Rosenberg, 2014; Wagner, 2013); to test general assumptions from art history (Brinkmann et al., 2014, 2019; Kesner et al., 2018; Sancarlo et al., 2020); or to detect variety and diversity among groups of viewers (Brinkmann, 2017; Pihko et al., 2011; Rosenberg \& Klein, 2015). However, to date, most eye tracking studies on art perception have been conducted in laboratories and with two-dimensional reproductions of artworks. While these studies have delivered remarkable results, they also have severe limitations: The difference between an original artwork and its reproduction is not only referential but essential; moreover, the effect of a museum's presentational context clearly cannot be studied in a laboratory setting. When moving from the lab to the museum, looking at art is embedded into socio-spatial constellations known to be far more engaging and satisfying (Brieber et al., 2014, 2015; Grüner et al., 2019; Specker et al., 2017).

Empirical evidence in visitor studies proves that seeing in the museum is everything but static. The combined activity of seeing and moving was already the subject of early visitor studies (Melton, 1935; Porter, 1938; Robinson, 1928) and continues to be investigated in timing and tracking studies up to the present day, with or without location-sensing technology (Yalowitz \& Bronnenkant, 2009). These studies have provided valuable insights into common viewing times and patterns when looking at art and reading labels (Carbon, 2017; J. K. Smith \& Smith, 2001; L. F. Smith et al., 2017); for establishing a Sweep Rate Index comparing dwell time in different sorts of exhibitions (Serrell, 1998, 2010) and for theoretically framing an exhibition visit in an attention-value model (Bitgood, 2013). Other, more exploratory studies have analyzed visitors' pathways and experiences in relation to the curatorial design of the exhibition space (Reitstätter, 2015; Skov et al., 2018; Tröndle et al., 2014). Methodologically, video recordings shifted the research focus from attentiongiving to multi-modal interaction analysis between artworks and co-present subjects (Christidou \& Diamantopoulou, 2016; Heath \& vom Lehn, 2010; Steier et al., 2015). Engagement with art is also mirrored in the more general literature on "entrance narratives" as the internal storyline that visitors bring with them (Doering \& Pekarik, 1996; Pekarik et al., 1999; Pekarik \& Schreiber, 2012) to the on-site museum experience (Black, 2005, 2018; Falk \& Dierking, 2013) in the context of informal and social learning theories (Crowley et al., 2014). Here, visitors are understood as active interpreters who engage with the given content in a structured perception scenario.

The very specific processes that occur in the visitor, i.e. the nature of art perception, are studied in the field of empirical aesthetics. Since Fechner's preschool of aesthetics ("Vorschule der Ästhetik," 1876) and in his tradition, empirical aesthetics have sought to provide more and more detailed descriptions of aesthetic experiences. These models comprise affective and cognitive sub-processes, range from perceptual to higher orders, and explain related cognitive processes (Leder et al., 2004) as well as affective preferences, emotions, and even transformative processes (Pelowski, Markey, et al., 2017). Regarding the value of art, an analysis of the commonalities in aesthetic experiences in museums, and beyond, by Pelowski, Forster et al. (2017) has revealed that memory seems common to all psychological approaches. Such studies agree that affective as well as meaning- and appraisal-related processes are essential. Pelowski et al. (2018) have also provided a taxonomy of responses to art that they empirically studied for two installations of the artist Ólafur Elíasson. In a prepost design, with questionnaires and partly also eye tracking, they were able to confirm the expected differences in appraisal strategies, enjoyment, and meaning making. 
Current technical developments of psycho-physiological devices are expected to boost visitor research and perception studies. Among these, "eye tracking may prove to be the most powerful tool for museum studies" (Milekic, 2010), as it provides precise data on the sensory viewing process. So far, however, eye tracking studies in museums have not reached their full potential. For example, Heidenreich and Turano (2011) recorded only four museum visitors at the Baltimore Museum of Art. Quiroga, Dudley, and Binnie (2011) studied six participants who viewed a single painting at the Tate Britain. At the Indianapolis $\mathrm{Mu}-$ seum of Art, Bachta et al. (2012) instructed visitors to sit in front of a remote eye tracker. Brieber, Nadal, Leder, and Rosenberg (2014) gave their participants a specific route to follow. Thalwitzer, Brinkmann, and Rosenberg used a calibration-free gaze tracker at the Kunsthistorisches $\mathrm{Mu}$ seum in Vienna in 2015, but with poor data quality (Dare et al., 2020). Wagner (2016) explored mobile eye tracking (MET) in regard to sculptures, albeit with only one, nonmoving subject. Wiseman et al. (2019) combined MET with motion capture to investigate how vision and body interact when perceiving a sculpture by Edgar Degas. The authors were unable to present results but exemplified the challenges of analyzing such a complex, multimodal data set. With regard to paintings, Walker et al. (2017) conducted a remarkable MET study in the Van Gogh Museum in Amsterdam. However, the researchers used fiducial markers displayed around the frames (altering the museum display), were continuously present, and had the participants follow fixed positions and viewing times. In the aforementioned study on installation art, in which Pelowski et al. (2018) recorded eye movements from twentyfour participants, these were able look at the exhibition without a pre-given path or time restrictions. Nonetheless, due to the small sample size and the fact that all participants were psychology students, they concluded that "this topic remains a largely under-explored avenue for future empirical work" (p. 20).

In addressing the current limitations of MET studies in museums, we need to strive for the most authentic study conditions and larger sample sizes in order to reach ecologically valid and generalizable findings. This was the aim and case of our study "Belvedere Before and After." We seized the opportunity provided by the museum's redisplay of its permanent collection-something that occurs only once every two decades or so- to analyze visitors' approaches to the same artworks in two different display constellations. The study was conducted as a collaboration between the Laboratory for Cognitive Research in Art History (CReA) at the Department of Art History of the University of Vienna, the Perception Engineering Group at the Department of Computer Engineering of the University of Tübingen, the Research Focus Empirical Visual Aesthetics (EVAlab) at the Department of Psychology of the University Vienna, and the Austrian Gallery Belvedere. This allowed us to combine the expertise of art historians, museologists, psychologists, and computer scientists. Overall, the study benefited from the comparison of two realistic display conditions (not artificially set up for research purposes), implemented an unconstrained study design (working with regular museum visitors who experienced the exhibition in natural groups and according to their own preferences), and managed to collect a large data sample (259 participants in total).

However, applying MET in a large-scale field study poses some technical challenges and comes with restrictions in data analysis. While we were able to demonstrate that MET technology is advanced enough to record data in such an unconstrained study design (Santini, Brinkmann, et al., 2018), it also became evident that reported MET data still lacks accuracy (e.g. with respect to eye movements within single artworks) and is not yet able to provide automatically reported semantic mappings (e.g. with respect to eye movements between artworks). Since the output of the eye tracker are gaze positions in the scene camera's video rather than coordinates of the museum space, we opted for the manual coding of the videos with respect to our objects of interest, i.e. mainly artworks and labels.

This paper presents the specifics of our field study and discusses the results of initial data analysis - focusing on the parameter of viewing time and a sub-sample of 100 participants.

\section{Methods}

In accordance with the necessities of a field study on art perception embedded in an authentic museum experience, our research approach was exploratory and guided by an open research question: How does the display influence the way people see and experience art in a museum? This question relates to the institutional, curatorial, and spatial frameworks that provide a script for visitors to view different artworks and stimulate their subjective meaning- 
making processes. Conducting a study in ecologically valid conditions means that it is neither possible nor desirable to isolate and control single variables such as the number of artworks or people present. We therefore also did not formulate detailed hypotheses about the influence of the display on eye movements. Instead, we have tried to discern specific effects of the museum's rearrangement by applying and combining diverse analytical tools, a mixedmethods approach combining quantitative and qualitative methods: MET was complemented with self-reported visual and verbal data (subjective mapping) as well as detailed contextual information on visitors' backgrounds (questionnaire).

\section{Procedure}

The data collection took place January 22-28, 2018, for the first part "Belvedere Before" (hereafter BB), and from January 28 to February 3, 2019, for the second part "Belvedere After" (hereafter BA); in both cases from Monday to Sunday so as to cover an entire museum week with comparable seasonal and day-specific visitor profiles. Both parts of the study followed identical procedures (see video https:/crea.univie.ac.at/projects/belvedere-beforeand-after): First, visitors were informed about the study and invited to participate. Those who accepted signed a consent form and were equipped with one of the four available eye tracking devices consisting of a Pupil Labs Headset (Pupil Core) with two adjustable eye cameras and one scene camera capturing the participant's field of vision. The headset was connected to a Microsoft Surface Pro 4 tablet PC worn in a light backpack $(<1 \mathrm{~kg})$. The eye tracking data was recorded with the software EyeRecToo (Santini, Fuhl, Geisler, et al., 2017), and calibration was

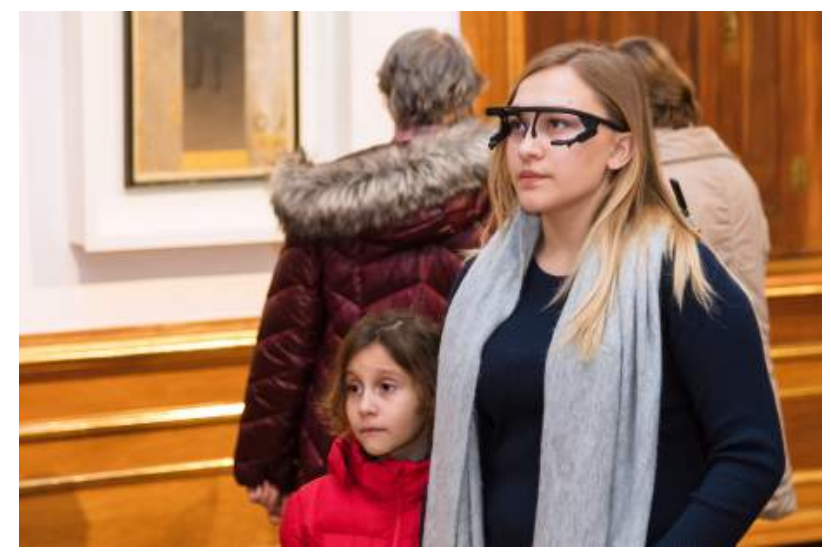

Figure 1. Individual exhibition visit with MET equipment (C) Department of Art History, University of Vienna conducted as proposed in CalibMe (Santini, Fuhl, \& Kasneci, 2017). This eye tracking software offers several distinct methods for implementing functionality in the eyetracking pipeline: We configured it with PuRe for pupil detection (Santini, Fuhl, et al., 2018a); with PuReST for pupil tracking (Santini, Fuhl, et al., 2018b); and with Grip for gaze estimation (Santini et al., 2019). After visiting an acclimatization room and the three rooms included in our study (see Figure 1), each participant took part in the subjective mapping task (see Figure 2) and answered the questionnaire. There was no monetary compensation, but participants received a small (unannounced) gift from the museum's shop.

\section{Mobile eye tracking}

MET has already been applied in museum studies (see above) and proven to be an insightful method due to the richness of the data gained, which also enables statistical analysis (Eghbal-Azar \& Widlok, 2013; Garbutt et al., 2020; Mayr et al., 2009). However, one of the main challenges of employing MET is extracting semantic meaning from the raw gaze data in relation to the stimuli (e.g., a painting on the wall of the museum), as these stimuli are consistently viewed from different perspectives. The eye movement data regarding the objects looked at (e.g. a specific artwork or label) is not a direct output of the recording software but a video of the scene camera with an estimated gaze point relative to the video frame. Moreover, regular fast-paced head movements (leading to motion blur in the captured images), the low dynamic range of the eye tracker's field camera, and frequent partial occlusion of artworks due to the presence of other visitors make the automatic labeling a challenging task. Given these technical

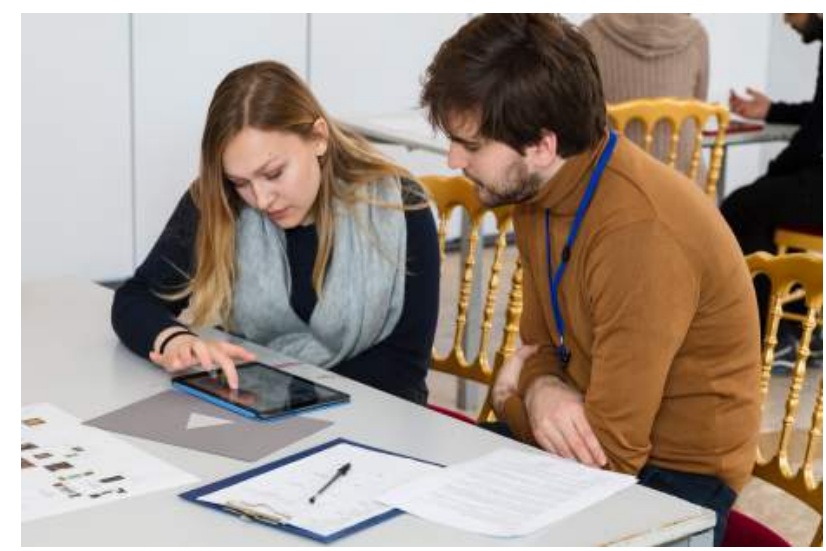

Figure 2. Subjective mapping following the exhibition visit (C) Department of Art History, University of Vienna 
limitations, we favored manual annotations for semantic mapping in this project - a labor intensive but more robust approach.

In our manual annotations, we assigned a code to each of the elements considered relevant in the exhibition space by means of the self-developed application Eye Movement Coder (current version 2.5). The particular object of interest could be selected from a predefined list, including all of the artworks, texts, people, media, and markers. As for the rooms before their rearrangement, fiducial markers were used to identify three artworks for potential automatic image recognition in later data analysis. The annotation process consisted of establishing and "stamping" the start and end time of continuous periods of attention on a specific object of interest. Each video was viewed and annotated by one coder, edited by a second, and finally checked by a supervisor. Four videos were randomly selected and annotated a second time by yet another person who was unaware of the first annotation. This facilitated a strong agreement between the two coders (Cohen's Kappa $=>0.84$ ). Taking advantage of this manual annotation process, we employed a functional definition of fixation (rather than a computational one) as judged by the human coders (Hessels et al., 2018). Additionally, multiple looks on objects of interests such as artworks and labels were summed up. Thus, our data analysis employed the parameter of viewing time per object of interest instead of algorithm-dependent metrics such as number of fixations or average fixation duration.

\section{Subjective Mapping}

While MET tracked the fast and jumping gaze between objects, people, and space, the subjective mapping allowed us to relate viewing behavior to individual meaning-making processes through visitors' a posteriori reports on their exhibition visits. Historically, such mapping techniques refer to mental maps as cognitive representations of spatial experience (Lynch, 1960) as well as to focused interviews using stimuli to elicit conversation (Merton \& Kendall, 1946). Mapping tools have also been developed for museum and visitor studies (Adams et al., 2003; Blanc, 2017; Christidou \& Reitstätter, 2020; Falk et al., 1997). For the subjective mapping applied in our study, we asked participants to mark the areas they remembered the strongest by drawing on an illustrated floor plan on a tablet. This task formed the basis for the simultaneous open interview wherein visitors reconstructed their exhibition experience, including reactions to specific works they could easily refer to on the map.

The process by which we prepared the subjective mapping data consisted of transcribing the interviews and annotating the artwork references. We named the artworks in brackets when a visitor declared, for instance, that he remembered "the paintings of Van Gogh [Auvers a2 10] and Munch [Männer a2_11], because I know the painter” (bas008). With the help of NVivo, a qualitative data analysis program, we categorized the interview statements according to the same coding grid as applied to the MET videos, differentiating between references to artworks, texts, and media. Additional codes, which pre-categorized topics and text segments for later content analysis, referred to the curatorial design of the three rooms as well as to museum and art interest in general.

\section{Questionnaire}

In order to broadly frame visitors' background and museum experience, we also used a comprehensive questionnaire (see Figure A1 in the Appendix) with six parts related to 1) artworks seen beforehand or personal highlights; 2) the exhibition experience in relation to display issues; 3 ) personal art interest, evaluated through the art interest scale of the Vienna Art Interest and Art Knowledge questionnaire (Specker et al., 2018); 4) specifics of the museum visit, e.g. alone, in a group or as tourists; 5) feedback on the use of MET, focusing on usability; and 6) socio-demographic background. The questionnaire was implemented with the survey program Qualtrics and displayed on an iPad handed to participants. Answers were mainly given on 7-point Likert scales. Statistical data analysis was conducted in $\mathrm{R}$.

\section{Participants}

Our total sample consisted of 259 visitors, of whom 109 participated in $\mathrm{BB}$ and 150 in $\mathrm{BA}$, with a mean age of $33.54(S D=14.12)$; mean age was comparable across both groups (BB: $M=34.9, S D=14.7$; $\mathrm{BA}: M=32.6, S D=$ 13.7). In total, 112 participants were male (BB: 46; BA: 66), 146 were female (BB: 63; BA: 83), and 1 person (in the BA group) did not have a binary gender identity. Most of our participants visited the museum in a group context (Total: $N=198$; BB: $N=77$; BA: $N=121$ ), with friends and families (Total: $N=159$; BB: $N=61$; BA: $N=98$ ) as well as pairs ( $N=104$; BB: 33 ; BA: 71$)$ as the most common group constellation. The majority of our participants 
were tourists (Total: $N=201$; BB: $N=81$; BA: $\mathrm{N}=120$ ), which was reflected in English being the predominant language of participation (Total: $N=202$; BB: $N=75$; BA: $N=127$; all others German) and most participants visiting the Belvedere for the first time (Total: $N=224$; BB: $N=$ 85; BA: $N=139$ ). Participant characteristics were thus comparable across our two groups.

For this paper, we have limited the analysis to a total of 100 participants due to the time-consuming nature of the manual annotation process. The selection of these 50-50 data sets out of the 109 in BB and 150 in BA was based on the data quality (e.g., slippage, Niehorster et al., 2020) and on the subset's representativeness of the whole data set with regard to gender (42 men, 58 women), age (mean $33.32, S D=13.45$ ), and visiting specifics (76 tourists, 24 non-tourists). Since the results showed an influence of the level of participants' art interest on viewing times, we checked if that interest differed between the BB and BA participants. This proved not to be the case (BB: $M=$ $49.59, S D=13.51$; BA: $M=48.97, S D=12.66 ; \mathrm{t}(257)=$ $0.38, p=.070$ ), i.e. the two subsets had similar means of art interest and were thus also comparable in this regard.

\section{Materials}

The stimuli of our study were original artworks, i.e., paintings and sculptures in an authentic museum context: the Baroque palace's venue, also known as the Upper Belvedere, which showcases the permanent collection of the Austrian Gallery Belvedere (see online database https://www.belvedere.at/en/collection). While the old display had been the subject of minor adaptations over the past two decades, the new display aims to provide a continuous course through 700 years of Austrian art history. The redisplay of the permanent collection aimed to offer "fresh approaches to these masterpieces" including "innovative thematic rooms, interspersing the chronological hanging through the periods of art and sparking a multilayered dialogue between the classics of art history and contemporary artists" (Austrian Gallery Belvedere, 2018). Since Gustav Klimt's paintings are the best-known works of the museum, we chose three rooms with his artworks and those by artists of his time for our study.

These rooms underwent three major display changes during the museum's rearrangement: First, where the old display used a variety of wall colors, the new one relies on uniformly white walls. This goes hand in hand with specific curatorial styles: While the bluish-tinted wall colors of Rooms 1 and 2 of the BB constellation reference either the salon presentation style of the $19^{\text {th }}$ century or postmodern wall color experiments, the new BA display relates to the dominant presentation mode of the $20^{\text {th }}$ century, the "White Cube," which highlights single objects in a reduced setting. The white background is also used for the presentation of the core Klimt piece "The Kiss," which is now displayed on a free-standing wall at the end of the room sequence. Earlier, "The Kiss" had been shown in Room 3, embedded in a black side wall, with his other works presented on white walls, aside from the red and black background for the small-format painting "Girlfriends (Water Serpents I)."

Second, the art historical narration in the single exhibition rooms has changed drastically. This includes a new exhibition course, with most of the pieces of our set now in the East wing instead of the West wing of the building. In BB the course of the rooms synthesized a narration that led from works by Hans Makart, the most successful painter in Vienna before Klimt (in our acclimatization room), to the presentation of the Viennese Secession (in Rooms 1 and 2) to a rich compilation of Klimt's works including the most famous, "The Kiss" and "Judith," at opposite far end walls (in the large Room 3). In BA, Klimt's paintings are no longer presented together in one large room, but distributed according to chronology and motifs; moreover, they are now matched with works by fellow contemporary artists. Besides curatorial reasons, this

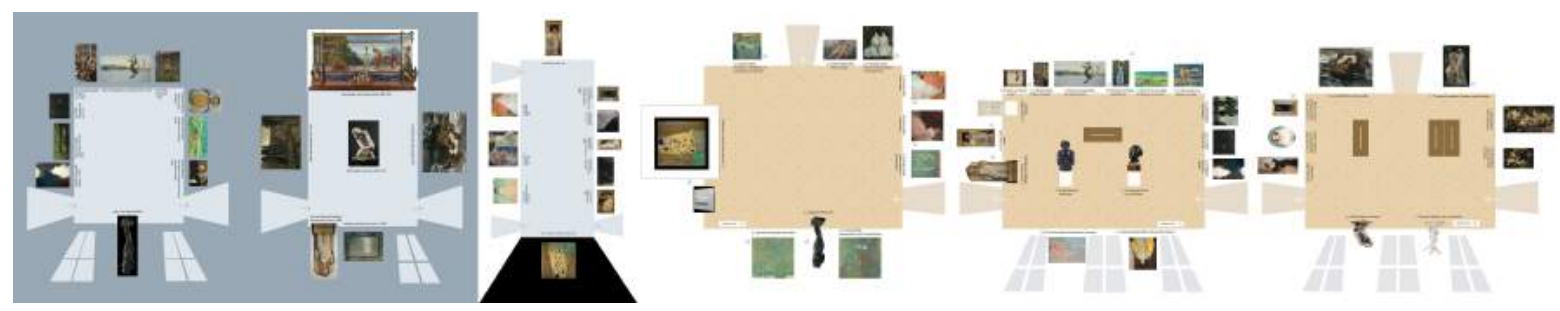

Figure 3. Map with 26 artworks in BB and map with 35 artworks in BA 
change was intended to affect the stream of visitors eager to see Klimt's works. The crowded situation of the single Klimt room in the BB setting was equalized by spreading his works over several rooms. The new BA display includes a variety of smaller thematic units, showing more works by more artists: Vincent Van Gogh's "Plain of Auvers," Giovanni Segantini's “The Evil Mothers," and Max Klinger's "Crouching Woman" have lost the central position they held in BB. They are now part of a long row of works by artists of the Viennese Secession. The BA display also shows more sculptures (seven instead of three), mainly positioning them close to the walls in line with the paintings or alongside the room passages.

Third, another major change was the introduction of interpretive labels (Serrell, 2015, p. 19-29), which were completely missing before; these take the forms of introductory room texts and captions for some artworks. The new display thus represents a shift from the simple identificatory label as the only textual information source in BB to a three-layered information structure in BA. In this way, texts on white stelae, as a first layer, offer short introductions to each room ("Vienna around 1900: All the World's a Stage" in Room 1; "The Secession" in Room 2; "Gustav Klimt" in Room 3). Additionally, the stelae include a sketch and a brief text concerning the historical decoration and function of each room. A second layer (consistent with that of BB) is each artwork's identification label (i.e., artist, place, year of birth and death, title and year of the artwork, technique, dimensions, and - where relevant - audio guide or sign language number; a new addition is information regarding the artwork's provenance). As a third layer, newly added captions on six out of thirty-five artworks (or four out of the thirteen presented in both BB and BA) provide information on the artwork's context, theme, and style. While the bilingual language structure with German and English has remained, the visual appearance of the labels has changed from the former white or dark grey letters pasted on the walls to cardboard labels with grey text against white backgrounds (and different shades of grey for language differentiation).

In summary, our material consisted of twenty-six artworks in BB (including three sculptures) and thirty-five artworks in BA (including seven sculptures) (see Figure 1, Table A1, and A2 in the Appendix). Thirteen artworks were shown in both display conditions, with four of them receiving new interpretive labels in the form of captions in BA.

\section{Results}

As outlined above, our study was conducted as field research in an authentic exhibition setting, where we investigated visitor behavior at two different points in time. The results of this first data analysis report the changes and consistencies that we encountered when comparatively analyzing the BB and BA data. Starting with a MET usability note, results on the general distribution of attention are followed by those on time spent viewing artworks, distinguishing between painting and sculpture. Further, we report findings on specific artworks in the focus of attention and the combined activity of looking at art and reading text, including the influence of personal characteristics.

\section{Usability}

The usability of the MET equipment was assessed in our questionnaire. An evaluation of the results for the BB data has already been published in Santini, Brinkmann et al. (2018). We ran t-tests for both data sets $(n=259)$ and found no significant differences in usability between $\mathrm{BB}$ and BA $(p<.05)$. Questions, to be answered on 7-point Likert scales $(1=$ not all, $7=$ very much), included one about the influence of the equipment on art experience: "My art perception has changed because of the eye-tracking equipment". In general, people indicated that their experience was not influenced by wearing the eye tracking glasses (BB: $M=2.35, S D=1.64$; BA: $M=2.54, S D=$ 1.71). This supports the idea that MET is a valid and reliable technology for registering the museum gaze and for decoding the display effect.

\section{General distribution of attention}

The annotated MET videos from the 50:50 participants resulted in a total time of $34,869 \mathrm{sec}(9 \mathrm{~h} 41 \mathrm{~min} 9 \mathrm{sec})$ in the BB and 54,315 sec (15 h $5 \mathrm{~min} 5 \mathrm{sec})$ in the BA constellation, counting the time from the first to the last video annotation in the three rooms. This means that the average dwell time per visitor increased from 11:37 min to 18:06 min. However, the dimensions of the rooms had also changed (see Materials above), with an increase in size from $305.20 \mathrm{~m}^{2}$ to $387.70 \mathrm{~m}^{2}$, as did the number of artworks displayed, from twenty-six to thirty-five. Nevertheless, we observed an increased awareness per square meter as visitors looked at $26.26 \mathrm{~m}^{2}$ per minute in $\mathrm{BB}$ and at $21.41 \mathrm{~m}^{2}$ in BA on average. Comparison of the distribution of attention in BB and BA (see Table 1) shows a temporal dominance of looking at art in the BB setting, where 
almost no text and only very plain label information was offered. There, participants spent $20,068 \mathrm{sec}$ or $57.27 \%$ of their total measured time looking at artworks and only $2,472 \mathrm{sec}$ or $7.05 \%$ on reading text. This ratio changed in the BA setting, where additional interpretive labels resulted in participants spending $26,125 \mathrm{sec}$ or $48.10 \%$ of their total time looking at artworks and 11,443 sec or $21.07 \%$ reading text. While participants did not look at artworks for shorter periods of time in general (see Results below), the relation between looking at art and looking at text changed drastically from a rough $8: 1$ to $2: 1$ ratio. However, the ratios of spending time with media (audio guides, phones, photo cameras), looking at people (companions or other persons present), and other elements (non-annotated time looking somewhere else, e.g., at windows and floors) remained nearly the same. Although the participants of our study spent only 174 seconds or $0.50 \%$ with fiducial markers that were applied to three out of twenty-six artworks in the BB constellation (to enable an automatic image recognition potentially applied in later data analysis), we decided not to use markers in the BA constellation, as the MET videos proved a major distraction of attention towards the markers placed around the paintings in the authentic exhibition context.
Table 1. Cumulated viewing times in seconds and percentages in $\mathrm{BB}$ and $\mathrm{BA}$

\begin{tabular}{lllll}
\hline & \multicolumn{2}{l}{ Belvedere Before } & \multicolumn{2}{l}{ Belvedere After } \\
\cline { 2 - 5 } & sec & $\%$ & sec & $\%$ \\
\hline Artwork & 20,068 & 57.27 & 26,125 & 48.10 \\
Text & 2,472 & 7.05 & 11,443 & 21.07 \\
Media & 1,888 & 5.39 & 1,932 & 3.56 \\
People & 2,797 & 7.98 & 3,233 & 5.95 \\
Marker & 174 & 0.50 & $/$ & $/$ \\
Other & 7,644 & 21.81 & 11,582 & 21.32 \\
Total & 34,869 & 100 & 54,315 & 100 \\
\hline
\end{tabular}

\section{Time spent viewing artworks}

Regarding the average time visitors spent looking at artworks (see Tables 2 and 3), we note that the viewing time per artwork differs greatly: Some received very little and others considerable attention. In BB, the viewing times for the twenty-six artworks ranged from a mean viewing time of $56.94 \mathrm{sec}(S D=38.57)$ for "The Kiss" by Gustav Klimt to $4.91 \mathrm{sec}(S D=5.94)$ for "Calm Water" by Fernand Khnopff. In BA, there was an even broader range of viewing times between the thirty-five artworks. The longest mean viewing time with $57.92 \mathrm{sec}(S D=48.54)$ was, again, observed for the "The Kiss" by Klimt and the shortest mean viewing time of $2.10 \mathrm{sec}(S D=4.73 \mathrm{sec})$ for "Gustav Mahler" by Auguste Rodin.

Table 2. Viewing times in seconds for the 26 artworks and their labels in BB

\begin{tabular}{|c|c|c|c|c|c|c|}
\hline \multirow[b]{2}{*}{$\mathrm{N}^{\circ}$} & \multirow{2}{*}{$\begin{array}{l}\text { Belvedere Before } \\
\text { Abbreviated titles }\end{array}$} & \multicolumn{2}{|l|}{ Artwork } & \multicolumn{3}{|l|}{ Label } \\
\hline & & Mean $(S D)$ & Median & Mean $(S D)$ & Median & \\
\hline 1 & Kiss & $56.94(38.57)$ & 47.00 & $1.70(3.33)$ & 0.00 & \\
\hline 2 & Judgement & $38.87(38.16)$ & 29.22 & $2.60(4.29)$ & 0.00 & \\
\hline 3 & Bride & $37.37(29.26)$ & 29.42 & $2.53(3.02)$ & 1.43 & \\
\hline 4 & Judith & $24.44(21.68)$ & 19.10 & $1.69(2.04)$ & 0.77 & \\
\hline 5 & Fritza Riedler & $23.86(16.16)$ & 19.12 & $2.20(3.13)$ & 1.15 & \\
\hline 6 & Girlfriends & $21.19(20.11)$ & 15.75 & $2.93(3.73)$ & 2.07 & \\
\hline 7 & Evil Mothers & $21.03(18.66)$ & 15.58 & $2.41(3.01)$ & 1.43 & \\
\hline 8 & Pax & $20.50(18.22)$ & 14.85 & $1.50(2.89)$ & 0.00 & \\
\hline 9 & Sea Idyll & $15.66(12.81)$ & 12.45 & $1.93(2.44)$ & 1.45 & \\
\hline 10 & Josef Lewinsky & $13.26(11.45)$ & 11.57 & $3.05(2.82)$ & 2.47 & \\
\hline 11 & Plain Auvers & $13.15(12.69)$ & 11.40 & $2.77(3.67)$ & 1.63 & (continued) \\
\hline
\end{tabular}


Table 2. Continued.

\begin{tabular}{llllll}
\hline 12 & Amalie Zuckerkandl & $11.52(9.76)$ & 9.77 & $2.55(3.03)$ & 1.67 \\
13 & Largo & $10.72(13.17)$ & 7.65 & $1.77(2.32)$ & 0.83 \\
14 & Lady White & $10.17(8.24)$ & 7.83 & $1.18(1.41)$ & 0.87 \\
15 & Allegory Music & $9.06(7.37)$ & 7.95 & $2.15(2.64)$ & 1.53 \\
16 & Early Spring & $8.70(8.78)$ & 5.23 & $2.47(3.26)$ & 1.32 \\
17 & Painter Physician & $8.28(7.58)$ & 5.58 & $3.86(4.88)$ & 2.12 \\
18 & Lady Fireplace & $8.23(7.62)$ & 6.33 & $1.59(1.98)$ & 1.05 \\
19 & Pond & $7.34(5.81)$ & 5.62 & $2.00(2.94)$ & 1.40 \\
20 & Dachstein & $6.66(8.42)$ & 4.55 & $1.03(1.68)$ & 0.00 \\
21 & Nymph & $6.65(7.87)$ & 4.13 & $0.70(2.01)$ & 0.00 \\
22 & Crouching Woman & $6.27(12.69)$ & 1.57 & $0.14(0.60)$ & 0.00 \\
23 & Self-Portrait & $6.10(7.66)$ & 2.97 & $1.75(1.91)$ & 1.22 \\
24 & Twilight & $5.38(6.05)$ & 3.30 & $1.67(2.20)$ & 0.87 \\
25 & Eve & $5.09(6.78)$ & 2.63 & $0.00(0.00)$ & 0.00 \\
26 & Calm Water & $4.91(5.94)$ & 2.73 & $1.28(1.82)$ & 0.50 \\
\hline
\end{tabular}

Table 3. Viewing times in seconds for the 35 artworks and their labels in BA

\begin{tabular}{|c|c|c|c|c|c|c|}
\hline \multirow[b]{2}{*}{$\mathrm{N}^{\circ}$} & \multirow{2}{*}{$\begin{array}{l}\text { Belvedere After } \\
\text { Abbreviated titles }\end{array}$} & \multicolumn{2}{|l|}{ Artwork } & \multicolumn{3}{|l|}{ Label } \\
\hline & & Mean $(S D)$ & Median & Mean $(S D)$ & Median & \\
\hline 1 & Kiss & $57.92(48.54)$ & 42.58 & $14.09(21.61)$ & 1.80 & \\
\hline 2 & Evil Mothers & $30.58(33.39)$ & 22.32 & $4.75(5.01)$ & 2.75 & \\
\hline 3 & Judith & $30.30(31.02)$ & 21.67 & $16.51(17.51)$ & 8.27 & \\
\hline 4 & Fritza Riedler & $27.60(27.80)$ & 19.53 & $3.21(3.65)$ & 2.18 & \\
\hline 5 & Sonja Knips & $21.39(22.15)$ & 13.45 & $11.05(11.27)$ & 9.88 & \\
\hline 6 & Sea Idyll & $21.31(16.60)$ & 16.47 & $3.83(5.71)$ & 2.08 & \\
\hline 7 & Forester's House & $20.12(24.79)$ & 10.38 & $4.20(4.80)$ & 2.55 & \\
\hline 8 & Lady Black & $19.88(17.65)$ & 13.73 & $4.11(5.00)$ & 2.90 & \\
\hline 9 & Antique Sacrifice & $18.61(19.25)$ & 13.72 & $3.68(4.33)$ & 2.90 & \\
\hline 10 & Josef Lewinsky & $18.15(25.05)$ & 9.67 & $14.74(18.27)$ & 6.60 & \\
\hline 11 & Plain Auvers & $15.84(18.20)$ & 9.93 & $13.50(16.33)$ & 6.07 & \\
\hline 12 & Orpheus Eurydice & $14.69(19.25)$ & 7.87 & $3.64(5.65)$ & 2.08 & \\
\hline 13 & Cottage Garden & $14.40(14.83)$ & 8.25 & $2.08(2.41)$ & 1.13 & \\
\hline 14 & Donaulände Summer & $13.85(16.37)$ & 10.57 & $3.60(3.72)$ & 2.60 & \\
\hline 15 & Seashore & $13.83(14.24)$ & 10.90 & $4.42(5.82)$ & 2.22 & \\
\hline 16 & Flowering Poppies & $12.98(16.32)$ & 7.12 & $1.84(2.79)$ & 0.53 & \\
\hline 17 & Emotion & $12.83(14.52)$ & 6.75 & $3.16(3.39)$ & 2.33 & \\
\hline 18 & Schloss Kammer & $12.82(12.34)$ & 8.87 & $4.63(5.43)$ & 3.60 & \\
\hline 19 & Sisters Fey & $12.78(16.43)$ & 3.37 & $8.00(10.72)$ & 2.07 & \\
\hline 20 & Therese Bloch-Bauer & $12.23(15.37)$ & 8.45 & $3.18(3.57)$ & 2.07 & \\
\hline 21 & Marie Kerner & $12.18(8.94)$ & 9.65 & $4.39(4.58)$ & 3.05 & (continued) \\
\hline
\end{tabular}


Table 3. Continued.

\begin{tabular}{llllll}
\hline 22 & Dante Vergil & $12.10(13.23)$ & 9.03 & $4.17(5.29)$ & 2.48 \\
23 & Nymph & $11.53(18.16)$ & 6.38 & $3.35(4.17)$ & $2.27(3.58)$ \\
24 & Lost & $11.53(14.93)$ & 7.08 & $3.18(3.85)$ & 2.60 \\
25 & Pond & $11.01(21.71)$ & 5.90 & $3.06(4.46)$ & 1.37 \\
26 & Visitation & $10.75(12.87)$ & 5.05 & $2.67(2.61)$ & 1.78 \\
27 & Early Spring & $9.47(9.40)$ & 6.02 & $2.64(3.23)$ & 1.97 \\
28 & Twilight & $8.86(10.89)$ & 4.12 & $2.09(4.66)$ & 0.00 \\
29 & Cupid Psyche & $8.36(10.22)$ & 5.98 & $1.48(2.02)$ & 0.08 \\
30 & Eve & $7.40(13.73)$ & 2.30 & $2.59(3.08)$ & 1.33 \\
31 & White Poplars & $5.67(5.71)$ & 3.93 & $1.77(3.05)$ & 0.43 \\
32 & Crouching Woman & $4.19(6.85)$ & 2.38 & $1.47(2.54)$ & 0.82 \\
33 & Woman Bathing & $3.12(3.98)$ & 1.48 & $1.03(2.93)$ & 0.00 \\
34 & Beethoven & $2.13(5.03)$ & 0.53 & $0.68(1.47)$ & 0.00 \\
35 & Gustav Mahler & $2.10(4.73)$ & 0.52 & & \\
\hline
\end{tabular}

Comparison of attention per artwork in the three rooms from BB (with twenty-six artworks) and BA (thirty-five artworks) reveals only a small decline of the mean viewing time from $15.44 \mathrm{sec}(S D=21.18)$ to $14.93 \mathrm{sec}(S D=$ 21.25). Interestingly, this decline is not even present for the art form of painting; here, the mean viewing time slightly rises from $16.67 \mathrm{sec}(S D=21.97)$ to $17.27 \mathrm{sec}(S D$ $=22.55)$. Regarding the art form of sculpture, we see a small decline from the mean viewing time of $6.00 \mathrm{sec}(S D$ $=9.43)$ to $5.55 \mathrm{sec}(S D=10.69)$ in the BA presentation, where seven instead of three sculptures were presented in the three rooms (see Table 4). This means that, although a higher number of paintings and sculptures was presented in the BA constellation, the average attention span per artwork only decreased slightly.

Table 4. Viewing times in seconds per painting, per sculpture and per artwork in BB and BA

\begin{tabular}{lllll}
\hline & \multicolumn{2}{l}{ Belvedere Before } & \multicolumn{2}{l}{ Belvedere After } \\
\cline { 2 - 5 } & Mean $(S D)$ & Median & Mean $(S D)$ & Median \\
\hline Sculpture & $6.00(9.43)$ & 2.77 & $5.55(10.69)$ & 1.72 \\
Painting & $16.67(21.97)$ & 9.97 & $17.27(22.55)$ & 9.80 \\
Artwork & $15.44(21.18)$ & 8.58 & $14.93(21.25)$ & 8.07 \\
\hline
\end{tabular}

\section{Painting versus sculpture}

Consequently, the major difference we found in comparing the mean viewing time per artwork in BB and BA is not related to the difference of display but of art form, i.e., painting versus sculpture. This observation regarding a preference in art forms is also supported by the specific viewing time ranks detected in $\mathrm{BB}$ and $\mathrm{BA}$ (see Tables 2 and 3). In BB, the three sculptures "Half-figure of a Nymph ('Vivien')" by Fernand Khnopff, "Eve" by Auguste Rodin, and "Crouching Woman" by Max Klinger occupy the lowest ranks, i.e. 21, 22, and 25 (out of twentysix). In BA, the seven sculptures (including the three just mentioned, plus "Cupid and Psyche" by Theodor Friedl, "Woman Bathing" by George Minne, "Gustav Mahler" by Auguste Rodin, and "Beethoven" by Max Klinger) also occupy the lowest ranks, i.e. 23, 29, 30, 32, 33, 34, and 35 (out of thirty-five). Thus, the MET data clearly shows less interest in sculpture (or even a neglect of it) than in painting. This correlates with findings from the questionnaire and subjective mapping. Visitors indicating in the questionnaire that they were mainly interested in painting proved predictive of a longer viewing time for paintings $(R 2=.03, F(1,98)=2.66, p=.11, B=43.75)$. Similarly, visitors indicating that they were mainly interested in sculpture proved predictive of a longer viewing time for sculpture $(R 2=.03, F(1,98)=2.71 p=.10, B=4.39)$. Both correlations were assessed with a linear regression; however, neither of these analyses was significant and the 
explained variance was very low. Moreover, the subjective mappings indicate a preference for painting over sculpture when visitors said they "didn't look much at the statues" (ba-s009), "don't remember seeing the statues" (ba-s012), or found them "not very interesting" (ba-s038), especially in BA. However, this is not a universal rule, as some visitors also emphasized their special interest in sculptural works.

Going beyond this general, weakened attention pattern regarding the art form of sculpture, we can discern a display effect among the three sculptures exhibited in both constellations (see Tables 2 and 3). While the viewing time of "Eve" slightly increased (BB: $M=5.09 \mathrm{sec}, S D=6.78$; BA: $M=7.40 \mathrm{sec}, S D=13.73)$, "Crouching Woman" attracted less attention (BB: $M=6.27 \mathrm{sec}, S D=12.69$; BA: $\mathrm{M}=4.19 \mathrm{sec}, S D=6.85)$, and "Half-figure of a Nymph ('Vivien')" clearly gained in attention (BB: $M=6.65 \mathrm{sec}$, $S D=7.87$; BA: $M=11.53 \mathrm{sec}, S D=18.16)$. In the case of "Eve," we encountered the interesting case that none of the $50 \mathrm{BB}$ participants looked at the label (being placed far away from the work); thus, no one could easily attribute the work to Rodin. In the case of "Crouching Woman" by Klinger - the only artwork among the thirteen presented in both conditions that was looked at for a shorter period of time after the museum's rearrangement —we can explain the loss of attention with its new positioning. While in BB, the sculpture was presented in the middle of the room in line with the artist's demand for viewers to walk around and see it from multiple perspectives (Gayk, 2011, p. 139; Treu, 1900), the BA presentation places the work close to a wall and in front of a mirror. The "Half-figure of a Nymph ('Vivien')", in contrast, gains in attention by being newly positioned next to the increasingly popular "Judith" by Klimt (see Results below). This new position contributes spatially, as the sculpture is positioned directly in the default line of sight when entering the second room, as well as in terms of content, as visitors in their meaningmaking confront and compare two artworks depicting seductive women.

\section{Specific artworks in the focus of attention}

Comparing the viewing times for the thirteen artworks that were both presented in BB and BA (see Figure 4 as well as Table A3 and A4 in Appendix), we detect a clear rise of attention after the rearrangement of the rooms. The mean viewing time per artwork increased from $15.98 \mathrm{sec}$ $(S D=21.08)$ to $19.55 \mathrm{sec}(S D=27.77)$. These results show that the new BA presentation generally stimulates visitors to spend more time with these artworks, with a mean attention shift of $22.34 \%$ per work. However, the ranking

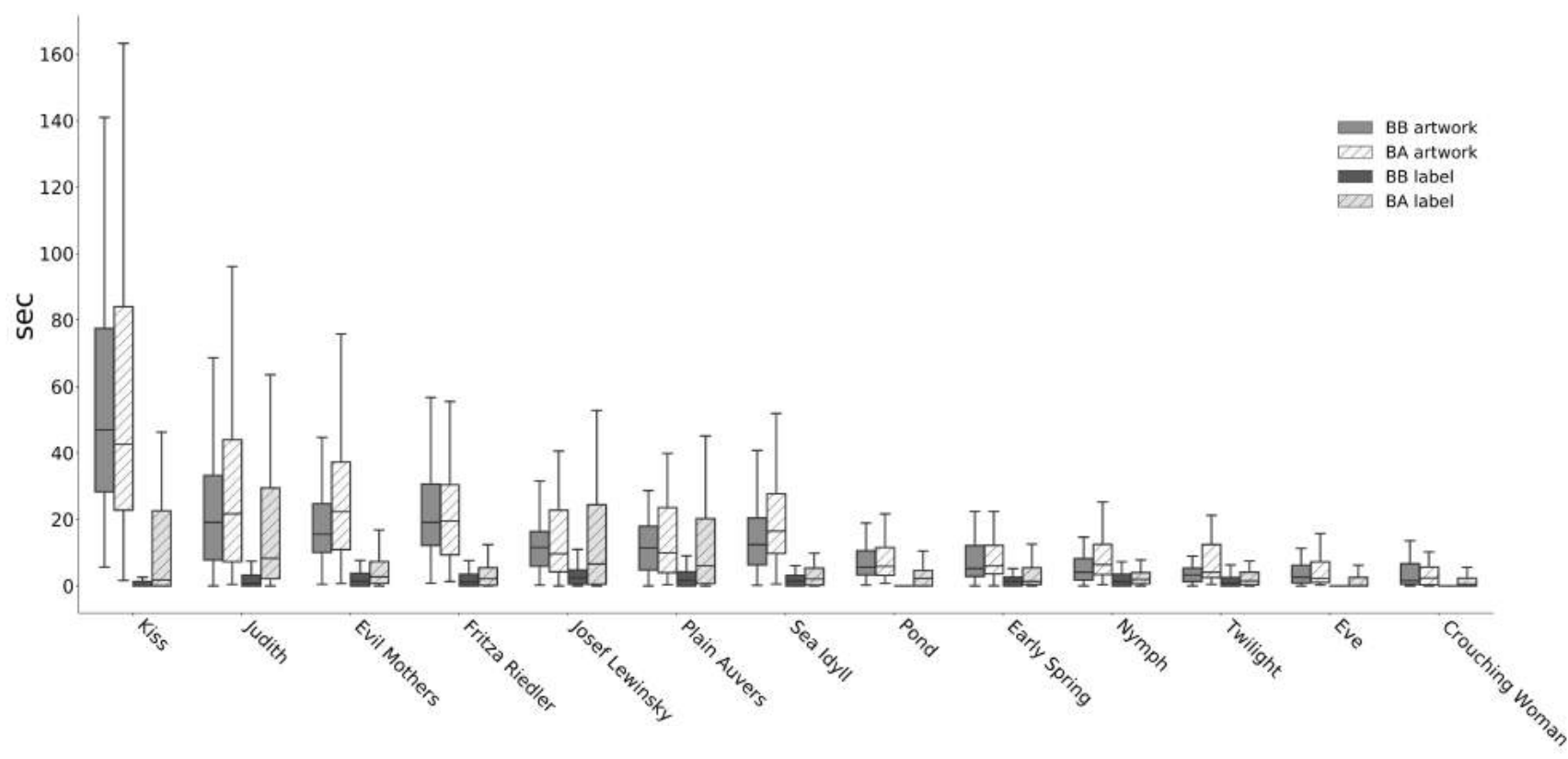

Figure 4. Average viewing times in seconds for the 13 artworks in BB and BA 


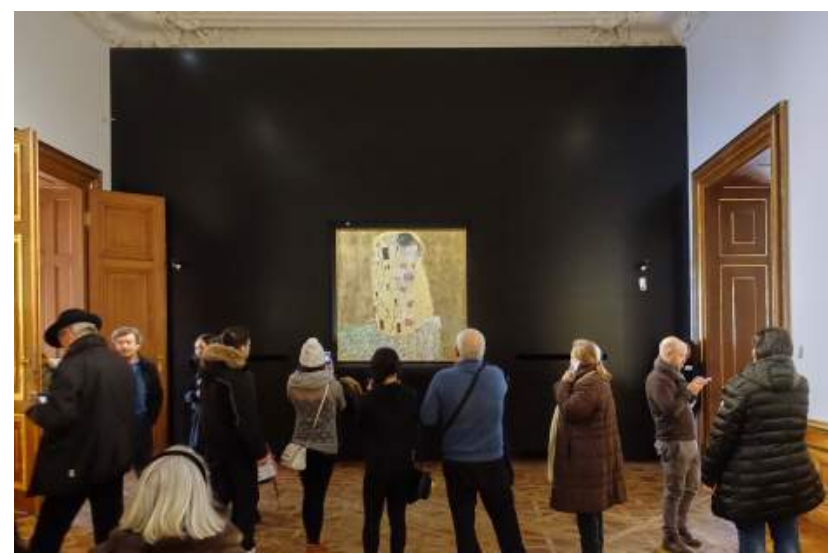

Figure 5. Installation shot with "The Kiss" in BB (C) Department of Art History, University of Vienna

according to viewing times shows a strong consistency between the higher and lower ranks of these thirteen artworks in BB and BA. Regardless of their display, certain artworks remain in the focus (see ranks 1-7), while others consistently receive less attention time (see ranks 8-13). Among the artworks in the focus of attention, there is of course "The Kiss," (see Figures 5 and 6) as participants often stated in the subjective mappings when they recalled their exhibition visit. This is not surprising, as "The Kiss" is the most prominent artwork of the museum and one that most visitors were already familiar with, having seen it before either in the original or as a reproduction (BB 77.98\%, BA: $74.67 \%$ ). In addition, works by widely known artists such as Klimt, van Gogh or Munch led to a heightened awareness, as visitors felt they "had to stop because it was from a famous painter" (ba-s075) or "of course [...] had to pay attention" (bb-s001) to these works.

In comparison to other artworks in the higher ranks, where three out of seven change their ranks, "The Kiss" remains the clear number one in terms of attention time. More specifically, the artwork holds an extremely high mean viewing time of almost one minute in $\mathrm{BB}(M=56.94$ sec, $S D=38.57)$ as well as in BA $(M=57.92 \mathrm{sec}, S D=$ 48.54). Accordingly, "The Kiss" also received the highest number of looks (BB: $M=27.62, S D=25.76$; BA: $M=$ $28.02, S D=23.25)$ compared to the average number of looks per artwork (BB: $M=7.58, S D=8.69$; BA: $M=$ $9.08, S D=10.28)$. The repeated returns to the work can be ascribed to the fact that the exhibition room tends to be crowded (which leads visitors to look at other visitors, or at other artworks, while waiting to look at "The Kiss") and

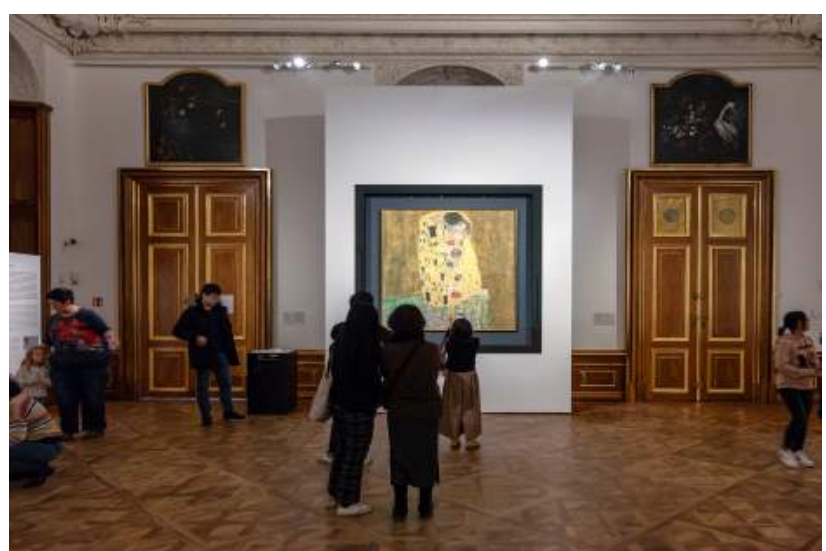

Figure 6. Installation shot with "The Kiss" in BA

(C) Department of Art History, University of Vienna

the need to evaluate the famous artwork for oneself in several steps. Due to this viewing context, "The Kiss" consistently required time to consume - although with differing conclusions. Many of the statements from the subjective mapping make it clear that the work was remembered for being famous. A small group of responses further demonstrates that "The Kiss" is a piece that polarizes: While for some visitors the artwork was the principal reason to come to the museum, with enthusiastic reactions such as "it made me feel loved, because it just depicts love" (bbs004), other visitors found the piece "famous but [...] not interesting at all" (bb-s006) or simply too "commercial" (ba-s126).

While there is almost no difference of viewing time between BB and BA for "The Kiss," two other artworks, "The Evil Mothers" (BB: $M=21.03 \mathrm{sec}, S D=18.66$; BA: $M=30.58 \mathrm{sec}, S D=33.39)$ and "Judith" " (BB: $M=24.44$ sec, $S D=21.68$; BA: $M=30.30 \mathrm{sec}, S D=31.02$ ), experienced the greatest display effect in terms of increased mean viewing times (see Figures 7, 8, 9 and 10). Both of them are now located in the Secession room and aligned with more works on the wall. This new group presentation would not have led us to assume that more attention would be given to the two artworks. In BA, however, "Judith" was intriguingly more often talked about, with forty-three out of fifty participants referring to the artwork in their exhibition reflections (as opposed to only twenty-three in BB). Apart from "Judith" being often described as a famous Klimt painting, depicting an attractive woman with golden ornaments, the artwork's interpretation deepened 


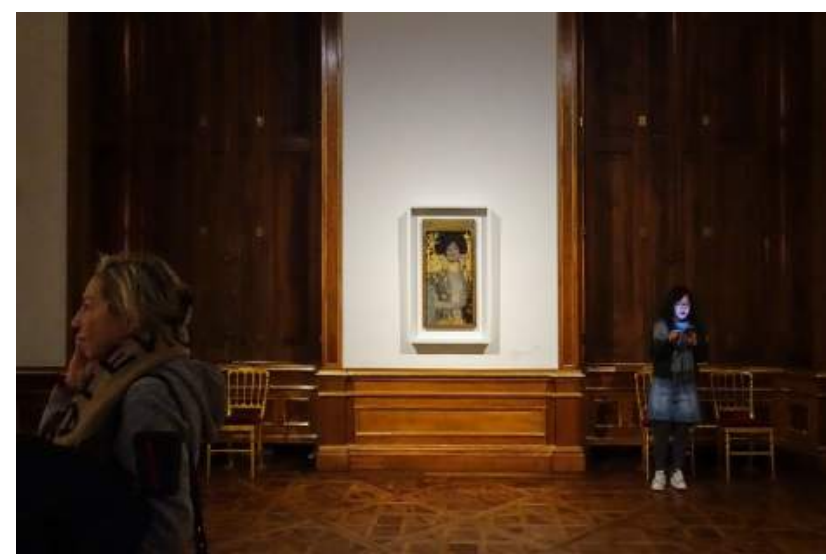

Figure 7. Installation shot with "Judith" in BB

(C) Department of Art History, University of Vienna

in BA with references to the biblical story of Judith and Holofernes or a general "gender trouble", as indicated in the caption.

Additionally, the sight-line positioning of "Judith" next to the sculpture "The Nymph" and in visual relation to the "Portrait of Therese Bloch-Bauer" led visitors to notice and refer to stylistic similarities in the proud and/or seductive depictions of the female subjects. While many visitors were familiar with "Judith" beforehand (BB: $60.55 \%$, BA: $74.67 \%$ ), this was not the case with "The Evil Mothers" (BB: $10.09 \%$, BA: $3.33 \%$ ). Here, the content analysis of the subjective mappings foregrounds the general attractiveness of the painting in both BB and BA. On the one hand, this means that the painting with its bright landscape, trees, and (hidden) women as well as babies stimulated "close looking." On the other hand, the ambiguous title,

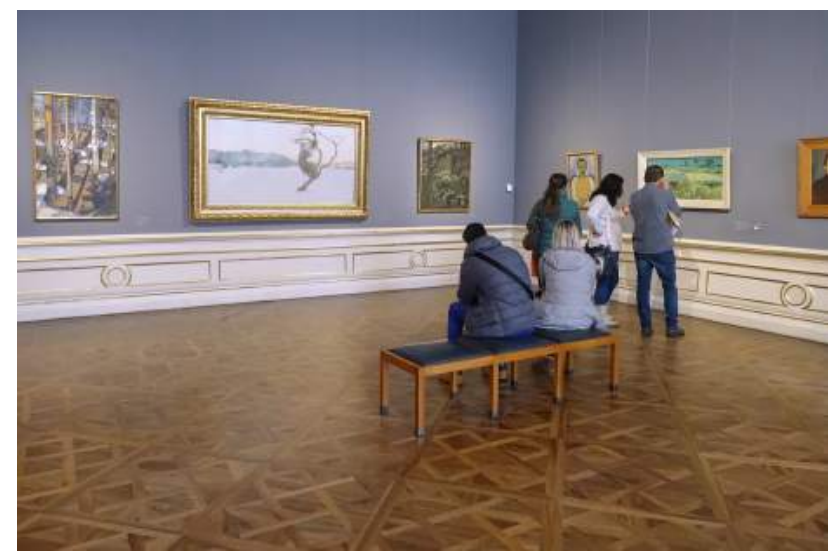

Figure 9. Installation shot with "Evil Mothers" (center) in BB (C) Department of Art History, University of Vienna

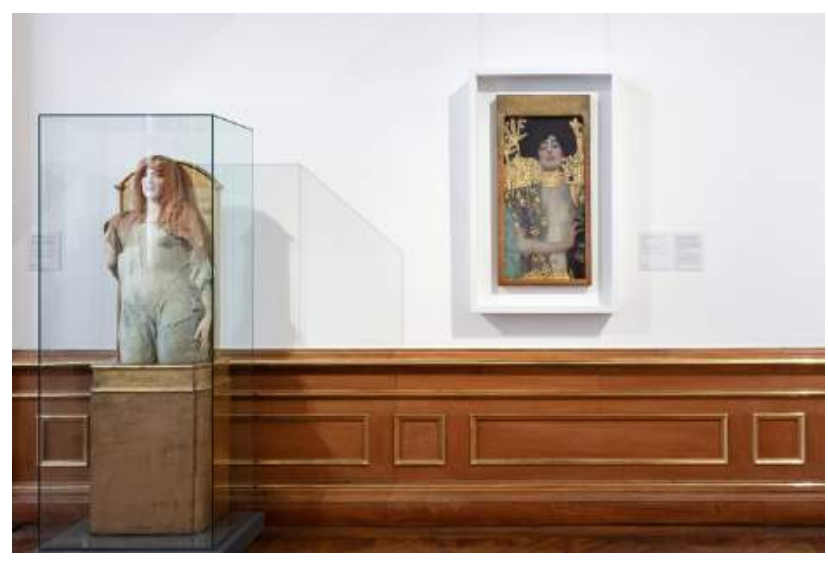

Figure 8. Installation shot with "Nymph" and "Judith" in BA (C) Department of Art History, University of Vienna

"The Evil Mothers," and the subtly suggested topics of motherhood and abortion stimulated further thoughts. In BA - with a mean viewing time increase of about ten seconds - this experience of a "double ambiguity" in the painting's style and content led to far-reaching interpretations and strong emotional reactions.

\section{Time spent looking at art and reading text}

Analyzing the time that visitors spent looking at the art and the accompanying labels (see Figure 10 as well as Tables A3 and A4 in the Appendix), we note a large shift from $\mathrm{BB}$ to $\mathrm{BA}$ : The mean total viewing time (including artwork and label) increased from $17.73 \mathrm{sec}(S D=21.96)$ to $26.14 \mathrm{sec}(S D=26.04)$ for the thirteen artworks that were presented in both settings. The introduction of new identification labels, and — in the case of four works - also

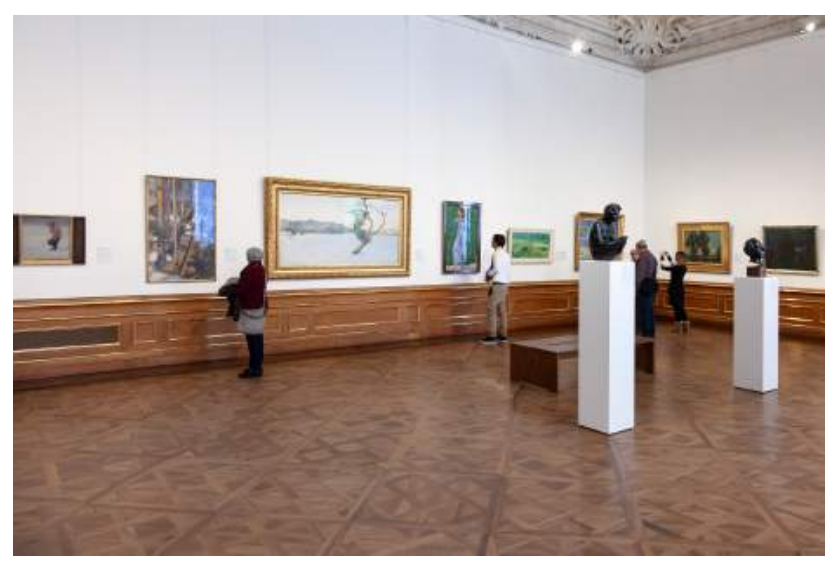

Figure 10. Installation shot with "Evil Mothers" (center) in BA (C) Department of Art History, University of Vienna 
captions with contextual information (as described in Materials), clearly proved beneficial towards mean total viewing times, with an increase of $47.43 \%$.

This heightened attention pattern is, not surprisingly, even more evident for the four artworks that were given additional captions (see Table 5). Here, the mean total viewing time even increased (from $\mathrm{BB}$ to $\mathrm{BA}$ ) from 29.25 $\sec (S D=29.64)$ to $45.26 \mathrm{sec}(S D=45.63)$. This is an increase of $54.75 \%$ in total viewing time, with an even more impressive rise - a quintupling, in fact - in reading time of $538.48 \%$. The introduction of these interpretive labels, we conclude, invited visitors to spend more time with those artworks, adding slightly to the viewing time and impressively to the reading time, as visitors accepted the new offer of (con)textual information.

Table 5. Viewing times in seconds for the 4 artworks and their labels in BB and BA (with additional captions)

\begin{tabular}{|c|c|c|c|c|c|c|}
\hline & \multicolumn{3}{|c|}{ Belvedere Before } & \multicolumn{3}{|c|}{ Belvedere After } \\
\hline & Artwork & Label & Artwork \& Label & Artwork & Label & Artwork \& Label \\
\hline & Mean $(S D)$ & Mean $(S D)$ & Mean $(S D)$ & Mean $(S D)$ & Mean $(S D)$ & Mean $(S D)$ \\
\hline Kiss & $56.94(38.57)$ & $1.70(3.33)$ & $58.64(38.71)$ & $57.92(48.54)$ & $14.09(21.61)$ & $72.01(57.84)$ \\
\hline Judith & $24.44(21.68)$ & $1.69(2.04)$ & $26.13(21.90)$ & $30.30(31.02)$ & $16.51(17.51)$ & $46.80(39.97)$ \\
\hline Josef Lewinsky & $13.26(11.45)$ & $3.05(2.47)$ & $16.31(11.97)$ & $18.15(24.05)$ & $14.74(18.27)$ & $32.89(38.58)$ \\
\hline Plain Auvers & $13.15(12.69)$ & $2.77(3.67)$ & $15.91(14.21)$ & $15.84(18.20)$ & $13.50(16.33)$ & $29.35(29.64)$ \\
\hline Total & $26.95(29.61)$ & $2.30(3.07)$ & $29.25(29.64)$ & $30.55(36.36)$ & $14.71(18.43)$ & $45.26(45.63)$ \\
\hline
\end{tabular}

In addition, the room texts exhibited in each space were generally well received by visitors, with mean viewing times of $16.85 \mathrm{sec}(S D=22.87)$ for the first room text, $21.32 \mathrm{sec}(S D=25.05)$ for the second, and $24.69 \mathrm{sec}(S D$ $=24.27$ ) for the third. We note an incremental increase in thematic interest from the first room text, "Vienna around 1900: All the World's a Stage," to the second, "The Secession," and again to the third, "Gustav Klimt." Here, the text about the popular artist was read by more visitors and for a longer time, with a median viewing time of $24.32 \mathrm{sec}$ (compared to $4.98 \mathrm{sec}$ for room text 1 and $9.17 \mathrm{sec}$ for room text 2). Moreover, the high standard deviation in reading time indicates that reading patterns varied widely among visitors. Analyzing these types of readers and deciphering the combined patterns of looking at artworks, reading text, and meaning-making, is a current subject of our further investigations.

The generally positive response to the additional text in BA is mirrored in the questionnaire, with visitors in BA $(M=4.63, S D=2.05)$ indicating that they would have liked more textual information to a lesser extent than did visitors in $\mathrm{BB}(M=5.43, S D=1.71 ; F(1,257)=11.13, p=$ .002 , generalized eta-squared $=0.04)$. In order to determine whether any of the visitors' personal characteristics (gender, age, level of art interest, being a tourist or not, visiting alone or with others, visiting for the first time) could predict viewing and reading time in general, we ran a series of linear regressions over the entire sample of participants. Of these, only "interest in art" significantly predicted (longer) viewing time; however, the level of art interest only predicted viewing time for artworks $(R 2=.06$, $F(1,98)=6.29, p=.01, B=6.70)$ and for total viewing time $(R 2=.05, F(1,98)=4.76, p=.03, B=9.68)$, but not for time spent reading text $(R 2=.00, F(1,98)=0.00, p=$ $.97, B=0.05)$

\section{Discussion}

With the redisplay of the permanent collection of the Austrian Gallery Belvedere in spring 2018, our study seized the unique opportunity to analyze viewing behavior before and after a museum's rearrangement. This endeavor was guided by the open research question: "How does the display influence the way people see and experience art in a museum?" Based on 1) the overall increase of viewing times for the artworks, 2) extended reading times, and 3) visitors' deeper engagement with the artworks in their exhibition reflections after the museum's rearrangement, we conclude that the display does, indeed, make a difference. It seems that the Austrian Gallery Belvedere delivers on its 
advertising claim that the Upper Belvedere could be experienced anew (Halwax, 2018). This display effect is not mono-causal but related to a range of factors or powers that interact as competing influences in the authentic setting of the exhibition, where visual, material and social contexts intermingle. These four identified powers, i.e. the display, the artwork, the art form, and the person, guide the following discussion, also indicating the limits and prospects of our work.

\section{The power of the display}

First of all, the display effect on viewing patterns depends on what visitors are given to see: In a rather classical art exhibition such as this, the objects presented were mainly artworks. The general distribution of attentionlooking at art at $57.27 \%$ in $\mathrm{BB}$ and $48.10 \%$ in BA-suggests that looking at art is the main visual activity and the dominant visual task performed when spending time in an art exhibition. In addition, the distribution of attention in $\mathrm{BB}$ versus $\mathrm{BA}$ shows that introducing just one more ingredient - interpretive labels - changed the time spent looking at art and reading text from a rough $8: 1$ to $2: 1$ ratio. At first glance, this increased interest in the texts could be interpreted as a sort of "distraction" from the art. But as the total times show, this is not so: Visitors did not spend less time on the artworks but more time with them looking and reading. This is in line with the timing and tracking conclusion that visitors with longer dwell times - such as in BA spending one minute with $21.41 \mathrm{~m}^{2}$ vs. $26.26 \mathrm{~m}^{2}$ in $\mathrm{BB}$, compared to an average Sweep Rate Index of 28 $\mathrm{m}^{2} / \mathrm{min}$ from a time database of more than 100 exhibitstend to do more things rather than fewer things in depth (Serrell, 1998, 2010). This conclusion is also supported by the mean viewing times of the thirteen artworks that were shown in both conditions, where twelve out of thirteen received more attention.

The "power of information" as part of the "power of the display" greatly contributed to the success of the BA presentation. Here, we observe a significant shift of attention, the total viewing time including the artworks and the labels increasing from $17.73 \mathrm{sec}(S D=21.96)$ to $26.14 \mathrm{sec}$ $(S D=26.04)$ for the thirteen commonly presented artworks and from $29.25 \mathrm{sec}(S D=29.64)$ to $45.36 \mathrm{sec}(S D=$ 45.63) for the four artworks that had additional interpretive labels. The captions with information on those works' contexts, themes, and styles worked especially well as stimulating gestures that signify (as the artworks might say) both "look at me" and "read about me." As visitors clearly followed this invitation to receive more contextual information, we conclude that interpretive text is a simple but very effective tool (from the curatorial and institutional side) of directing attention. The addition of text also proved to be beneficial towards visitors' meaning-making, extending the depth and range of interpretations, as exemplified in the case of "Judith." This value of interpretive text (rather than only identification labels) confirms that "part of the pleasure derived from looking at a painting stems from making a successful interpretation" (Russell, 2003, p. 99). Long-standing evaluation work furthermore attests that labels that "contain concrete visually referenced information" foster combined reading and looking patterns, plus social activities such as pointing and talking (Serrell, 2015, p. 328). Consequently, we suggest that museums employ the label communication tool more consciously in order to enable multimodal and social encounters with artworks and other visitors. Another suggestion is to equip more artworks with additional captions, not only those that are already famous or from famous artists. This could also work towards visitors' individual valueratio choices in exhibitions in terms of the costs (time and effort of reading) they are willing to invest to obtain the benefit (such as contextual information and ideas for interpretation) in specific situations (Bitgood, 2013, 83-91).

\section{The power of the artwork}

The "power of the display" as influential presentation mode is, however, very much counteracted by the "power of the artwork." No matter how the artworks are presented, a few specific artworks will always be in the focus of attention. It is noteworthy that visitors systematically spend very different amounts of time with different artworks, i.e. from the highest of almost one minute (BB: $M=56.94 \mathrm{sec}$, $S D=38.57$; BA: $M=57.92 \mathrm{sec}, S D=48.54)$ to the lowest of a few seconds (BB: $M=4.91 \mathrm{sec}, S D=5.94$; BA: $M=$ $2.10 \mathrm{sec}, S D=4.73)$. In addition, as shown by the ranking of the thirteen artworks that were presented both in $\mathrm{BB}$ and BA, it is the same group of artworks that attracts either higher or lower attention time. This insight substantially expands our understanding of typical art viewing times, since these have previously been tested with fewer, famous or well frequented works only (Carbon, 2017; J. K. Smith \& Smith, 2001; L. F. Smith et al., 2017). Most often, these "attention magnets" are commonly referred to as "highlights" (as on the Belvedere museum's website https://digital.belvedere.at/highlights) or, in tourist terminology, as "must sees and dos" (as on the travel blog 
shorturl.at/1MR27). This also means that the majority of visitors have seen them before, at least online. Following the spoken words of visitors, we suggest to name these "of course" artworks, as they are "of course" intensely looked at and strongly remembered.

In our set of artworks, "The Kiss" best demonstrates this "of course" status, joined by other works by "of course" artists such as Gustav Klimt, Vincent van Gogh, and Edvard Munch. This proves that fame and familiarity strongly influence our viewing behavior and enhance "the power of the artwork". For the world-famous "The Kiss", we detected the highest mean viewing time of almost one minute, comprising the highest mean number of 28 looks at the artwork per visitor, measured in both settings. This pattern of repeated returns and cumulative viewing time was already observed in a study with Gerhard Richter paintings (Carbon, 2017), but without specification of the number of looks as the tracking was done manually. A comparison between the high viewing time for and the numerous looks at "The Kiss" with the subjective mapping statements, however, reveals that this time focus cannot be directly linked to liking the artwork or having had a fulfilling viewing experience. Partly, we were also able to detect ambivalent reactions to this work, being so well known in popular culture. On the negative side, the work's celebrity combined with high expectations led some visitors to disappointment, disinterest or even distinction from the "masses" in the more or less crowded viewing situation on site. On the positive side, popularity led to excitement of some visitors, who could finally see the original or "the real thing" (bb-s010), following a path of (visual) anticipation. In the case of "The Kiss," we can thus corroborate the statement that "time is not quality" (Doering \& Pekarik, 2010 in their critique of Serrell's timing and tracking indices) per se. Clearly, it depends on the specific exhibition situation and visitors' individual perceptions whether investing viewing time and looks coincides with a positive art experience.

In contrast, the examples of "Judith" and "Evil Mothers"-works that received the highest viewing time increases after the museum's rearrangement - show that spending more time can come with an increase in the quality of the art experience. Here, "the power of the artwork" was enhanced by "the power of the display" in the new curatorial presentation. Our analysis demonstrates that it is the combination of eye-appealing style and thought-provoking story that these ever-strong artworks revealed even more to visitors when they spent more time with them. In BA, the already famous "Judith" even became the "star" of the Secession room due to this heightened attention pattern. To the work's advantage, it is now the only one by Klimt in the Secession room; it "seduces," as it were, the viewer's attention with the character's own gaze and her story. This focus is supported by the information concerning the Judith and Holofernes story that is offered in the newly added interpretive label and the possible comparison with other female portraits in the Secession room. "The Evil Mothers" by Giovanni Segantini demonstrates that artworks that are not as famous or previously familiar to visitors also have the potential to attract attention. Despite its relative unfamiliarity, "The Evil Mothers" still ranked high in $\mathrm{BB}$ and even higher in $\mathrm{BA}$, where it is the second-longest looked-at artwork after "The Kiss." The difference we note between the two display conditions is how close the looking was and how far the interpretations went, as "The Evil Mothers" invited visitors to delve even more into visual details and to think about its ambiguous title and story in BA. This quality effect, however, could not be attributed to specific display changes referred to in visitors' statements. Possibly, this effect was simply enabled by the availability of seating placed directly in front of the artwork, proving to be beneficial to viewing times (J. K. Smith \& Smith, 2001, p. 232).

\section{The power of the art form}

Looking at the lower rankings in viewing times, we additionally identified the "power of the art form" as an influential factor on viewing behavior. All three sculptures in $\mathrm{BB}$ and the seven in $\mathrm{BA}$ ranked at the lower end of the scale; the mean viewing time for sculptures amounted to less than half of the time for paintings in both settings: 6.00 $\sec (S D=9.43)$ versus $16.67 \mathrm{sec}(S D=21.97)$ in $\mathrm{BB}$ and $5.55 \mathrm{sec}(S D=10.69)$ versus $17.27 \mathrm{sec}(S D=22.55)$ in BA. A possible explanation for this striking dominance of paintings over sculptures might be visitors' expectations. As earlier research has shown, the influence on "entrance narratives" is extremely determinant in what people expect to see and, in consequence, are not only willing to see but will have seen when they leave the museum (Pekarik \& Schreiber, 2012). In the case of the permanent collection of the Austrian Gallery Belvedere, expectations are very much bound to the art form of painting, especially when they "come for a Kiss" (according to the museum's marketing campaign) or other of Klimt works. We assume that this pattern might be different when visitors expect to see 
sculpture primarily and not as part of an "extra" or a "side show." Moreover, the rather lateral position of sculptures in BA, being positioned close to walls or the pathway, enhanced this peripheral perception. This was especially true for the "Crouching Woman" by Klinger as the only artwork among the thirteen presented in both settings that was looked at shorter after the museum's rearrangement: While in BB one almost stumbled upon her "in the center [...] as a sculpture in a room of paintings" (bb-s030), in BA one can simply pass her by without the merest glance. This dominance of painting over sculpture contrasts, in part, with re-hanging experiments of the eMotion project, where sculptures evoked strong effects in the "force field" of the exhibition, even withdrawing attention from works on the wall. However, this effect depended on the size of the sculpture and its central position in the middle of the room (Tröndle et al., 2014 p. 162-169).

\section{The power of the person}

An important factor for the museum experience are the individual histories and psychological processes that visitors bring to the museum (Bitgood, 2013, p. 20). This dimension can be regarded as "the power of the person." In our study, however, we were able to prove that neither age, gender or the fact of being a tourist influenced viewing times. Regarding possible effects of being a tourist, however, our dataset might be misleading, since tourist visitors were overrepresented. The only variable that positively affected artworks and total viewing times was found in the level of art interest. In psychological theories of empirical aesthetics, this variable is regarded as central and often discussed in relation to art knowledge as the two main components defining art expertise (Leder et al., 2004; Pelowski et al., 2016; Pelowski, Markey, et al., 2017). More importantly, art expertise as a determinant of aesthetic experiences is emphasized by all major psychological theories, claiming that one's interest and knowledge about art changes one's orientation towards art. This affects not only the cognitive, higher-order level of processing of art; expertise has also been shown to change the evaluation of art more generally, as people with higher expertise generally appreciate art more (Leder et al., 2012).

At the same time, empirical data clearly demonstrates that art interest and art knowledge are two distinct dimensions (Specker et al., 2018). For reasons of practicality, i.e. the length of the questionnaire, our study included the art interest scale but not the art knowledge scale of the VAIAK questionnaire. However, the art interest scale does not only refer to subjective interest items but also asks precisely about behavior that would indicate an interest in art (e.g., how often people visit museums). Thus, people who report that they often visit art museums (or engage in other related behavior) would be expected to also spend more time in viewing art in the museum, since one is obviously more likely to pay more attention to things one is more interested in (Goller et al., 2019). It is noteworthy, however, that in regard to reading the texts that were available in the rooms, art interest had no effect on the time spent on them.

\section{Conclusion}

In conclusion, we note that the redisplay of the collection and the rearrangement of the museum had a measurable impact on how the artworks were viewed and experienced. Of course, unlike laboratory experiments with controlled manipulation of variables, it is not possible in such a field study to clearly ascribe changes to a specific factor. In the museum, indeed, the "power of the display" interacts with the "power of the artwork", the "power of the art form," and the "power of the person". However, the innovative combination of MET with other analytical methods did provide significant insights into these power relations.

The limitations of our study are consequently linked to the specificity of a field study where validity takes precedence over reliability. Far from entering into a lab versus museum debate, we suggest consciously opting for one or the other direction, ideally combining findings from both controlled and unconstrained studies as well as combining (mobile) eye tracking with other methods. With respect to MET data analysis, we hope to soon overcome the limitation of having to rely on manual data annotation. A data analysis program based on object recognition and machine learning would save analysts from spending countless hours in data preparation and enable more complex singleobject data analysis beyond the measuring of viewing time (e.g., viewing behavior with regard to form and content of specific artworks) as well as inter-object-related data analysis (e.g., gaze trajectories between artworks and people in crowded situations).

Powerful and accessible MET data analysis programs would also facilitate further analysis of the data collected in the "Belvedere Before and After" study moving beyond the scope of this paper to present first general results. Future work, departing from phenomena encountered in this 
exploratory study, will specifically investigate seeing in relation to other practices. This includes seeing and reading (to explore gaze patterns between image and text as well as corresponding meaning-making processes); seeing and using a smartphone (to empirically frame the impact of this digital tool on contemporary museum practice); as well as seeing and moving in an exhibition space (to investigate the numerous viewpoints in relation to the art forms of painting and sculpture). In these ways, then, we aim to further understand the museum gaze from multiple perspectives.

\section{Ethics and Conflict of Interest}

The authors declare that the contents of the article are in agreement with the ethics described in http://biblio.unibe.ch/portale/elibrary/BOP/jemr/ethics.html and that there is no conflict of interest regarding the publication of this paper. The study was approved by the ethics committee of the University of Vienna, participants signed a detailed consent form, and no visitors under 18 took part.

\section{Acknowledgements}

We would like to cordially thank the whole team of the Austrian Gallery Belvedere with its Scientific Director, Stella Rollig, for the collaboration and especially Margarete Stechl for the daily support. Our heartfelt thanks also go to Anna Cornelia Barbulesco, Jane Boddy, Max Douda, Anna Fekete, Judith Herunter, Sarah Hübler, Rebeka Jovanoska, Jisoo Kim, Katrin Kopp, Marthe Kretzschmar, Rosita Messmer, Kristina Miklosova, Adrian Praschl-Bichler, Rebekah Rodriguez, Stephanie Sailer, Rosa Sancarlo, Berna Selin Sayin, Hamida Sivac, Mariette Soulat, Julia Starke, Clara Swaboda, Magdalena Syen, Daniel Teibrich, Veronika Vishnevskaia, and Sophie Wratzfeld for their valuable help in data collection and data preparation. This research was supported in part by the Austrian Science Fund (FWF, grant P25821 and P27355) and the Vienna Science and Technology Fund (WWTF, grant CS15-036). Open access funding was provided by the University of Vienna.

\section{References}

Adams, M., Falk, J. H., \& Dierking, L. D. (2003). Things Change: Museums, Learning and Research. In M. Xanthoudaki, L. Tickle, \& V. Sekules (Eds.), Researching Visual Arts Education in Museums and Galleries (pp. 15-32). Kluwer Academic Publishers.

Austrian Gallery Belvedere. (2018). A New Look: The Permanent Collection Redisplayed (Press release). https://www.belvedere.at/sites/default/files/jartfiles/PM-Schausammlung-NEU-en.pdf

Bachta, E., J. Stein, R., Filippini-Fantoni, S., \& Leason, T. (2012). Evaluating the Practical Applications of Eye Tracking in Museums. Museums and the Web. https://www.museumsandtheweb.com/mw2012/pap ers/evaluating_the_practical_applications_of_eye_t .html

Beck, M. (2016). The Exhibition and the Display. In S. Lucy (Ed.), Exhibition (pp. 27-33). Whitechapel Gallery.

Bennett, T. (1995). The birth of the museum: History, theory, politics. Routledge.

Bitgood, S. (2013). Attention and value: Keys to understanding museum visitors. Left Coast Press.

Black, G. (2005). The engaging museum: Developing museums for visitor involvement. Routledge.

Black, G. (2018). Museum informal learning in the "Age of Participation": Our museums in 2030. Standbein Spielbein, 109(1), 10-21.

Blanc, M. (2017). Max Imdahls Ikonik und ihr positiver Einfluss auf die Entgrenzung des Wissens (L'Iconique de Max Imdahl et le décloisonnement des savoirs). Regards Croisés, 7, 67-80.

Brieber, D., Nadal, M., \& Leder, H. (2015). In the white cube: Museum context enhances the valuation and memory of art. Acta Psychologica, 154, 36-42. https://doi.org/10.1016/j.actpsy.2014.11.004

Brieber, D., Nadal, M., Leder, H., \& Rosenberg, R. (2014). Art in time and space: Context modulates the relation between art experience and viewing time. PLoS ONE, 9(6). https://doi.org/10.1371/journal.pone.0099019

Brinkmann, H. (2017). The Cultural Eye: Eine empirische Studie zur kulturellen Varianz in der Kunstwahrnehmung. Dissertation, Univ. of Vienna. 
Brinkmann, H., Commare, L., Leder, H., \& Rosenberg, R. (2014). Abstract Art as a Universal Language? Leonardo, 47(3), 256-257. https://doi.org/10.1162/LEoN_a_00767

Brinkmann, H., Williams, L., Rosenberg, R., \& McSorley, E. (2019). Does 'Action Viewing' Really Exist? Perceived Dynamism and Viewing Behaviour. Art and Perception, 27-48. https://doi.org/https://doi.org/10.1163/2213491320191128

Buswell, G. T. (1935). How People Look at Pictures: A Study of the Psychology of Perception in Art. The University Chicago Press.

Carbon, C. C. (2017). Art perception in the museum: How we spend time and space in art exhibitions. IPerception, 8(1), 1-15. https://doi.org/10.1177/2041669517694184

Christidou, D., \& Diamantopoulou, S. (2016). Seeing and Being Seen: The Multimodality of Museum Spectatorship. Museum and Society, 14(1), 12-32. https://doi.org/10.29311/mas.v14i1.623

Christidou, D., \& Reitstätter, L. (2020). From Map Using to Map Making: The Museum Experience Through Social Meaning Mapping. In M. Gresaldi \& I. S. Horn (Eds.), The Interdisciplinarity of the Learning Sciences, 14th International Conference of the Learning Sciences (ICLS) 2020 (Vol. 2, pp. 10871094). International Society of the Learning Sciences.

Crowley, K., Pierroux, P., \& Knutson, K. (2014). Informal learning in museums. In The Cambridge Handbook of the Learning Sciences (pp. 461-478). Cambridge University Press. https://doi.org/10.1017/CBO9781139519526.028

Dare, Z., Brinkmann, H., \& Rosenberg, R. (2020). Testing a Calibration-Free Eye Tracker Prototype at the Kunsthistorisches Museum in Vienna. Journal of Eye Movement Research, 13(2), Manuscript in preparation.

Doering, Z. D., \& Pekarik, A. J. (1996). Questioning the Entrance Narrative. Journal of Museum Education, 21(3), 20-23.

Doering, Z. D., \& Pekarik, A. J. (2010). Why Time Is Not Quality. Curator: The Museum Journal, 40(4), 249252. https://doi.org/10.1111/j.21516952.1997.tb01309.x
Eghbal-Azar, K., \& Widlok, T. (2013). Potentials and Limitations of Mobile Eye Tracking in Visitor Studies: Evidence From Field Research at Two Museum Exhibitions in Germany. Social Science Computer Review, 31(1), 103-118. https://doi.org/10.1177/0894439312453565

Falk, J. H., \& Dierking, L. D. (2013). The Museum Experience Revisited. Left Coast Press.

Falk, J. H., Moussouri, T., \& Coulson, D. (1997). The Effect of Visitors' Agenda on Museum Learning. Curator: The Museum Journal, 41(2), 107-120. https://doi.org/10.1111/j.21516952.1998.tb00822.x

Fechner, G. T. (1876). Vorschule der Aesthetik. Breitkopf \& Härtel.

Garbutt, M., East, S., Spehar, B., Estrada-Gonzalez, V., Carson-Ewart, B., \& Touma, J. (2020). The Embodied Gaze: Exploring Applications for Mobile Eye Tracking in the Art Museum. Visitor Studies, 23(1), $1-19$. https://doi.org/10.1080/10645578.2020.1750271

Gayk, I. (2011). Max Klinger als Bildhauer: Unter Berücksichtigung des zeitgenössischen französischen Kunstgeschehens. Verlag Dr. Kovac.

Goller, J., Mitrovic, A., \& Leder, H. (2019). Effects of liking on visual attention in faces and paintings. Acta Psychologica, 197, $115-123$. https://doi.org/10.1016/j.actpsy.2019.05.008

Grüner, S., Specker, E., \& Leder, H. (2019). Effects of Context and Genuineness in the Experience of Art. Empirical Studies of the Arts, 37(2), 138-152. https://doi.org/10.1177/0276237418822896

Halwax, N. (2018). TBWA: Eröffnungskampagne für Belvedere-Schausammlung. Horizont. https://www.horizont.at/agenturen/news/tbwaeroeffnungskampagne-fuer-belvedereschausammlung-64736

Heath, C., \& vom Lehn, D. (2010). Interactivity and Collaboration: New forms of participation in museums, galleries and science centres. In R. Parry (Ed.), Museums in a Digital Age (pp. 266-280). Routledge.

Heidenreich, S., \& Turano, K. (2011). Where does one look when viewing artwork in a museum? Empirical Studies of the Arts, 29(1), 51-72. https://doi.org/10.2190/EM.29.1.d 
Hessels, R. S., Niehorster, D. C., Nyström, M., Andersson, R., \& Hooge, I. T. C. (2018). Is the eye-movement field confused about fixations and saccades? A survey among 124 researchers. Royal Society Open Science, $5(8)$. https://doi.org/https://doi.org/10.1098/rsos.180502

Hughes, P. (2015). Exhibition design: An introduction. Laurence King Publishing.

Kesner, L., Grygarová, D., Fajnerová, I., Lukavský, J., Nekovářová, T., Tintěra, J., Zaytseva, Y., \& Horáček, J. (2018). Perception of direct vs. averted gaze in portrait paintings: An fMRI and eye-tracking study. Brain and Cognition, 125(June 2017), 88-99. https://doi.org/10.1016/j.bandc.2018.06.004

Leder, H., Belke, B., Oeberst, A., \& Augustin, D. (2004). A model of aesthetic appreciation and aesthetic judgments. British Journal of Psychology, 95(4), 489-508. https://doi.org/10.1348/0007126042369811

Leder, H., Gerger, G., Dressler, S. G., \& Schabmann, A. (2012). How art is appreciated. Psychology of Aesthetics, Creativity, and the Arts, 6(1), 2-10. https://doi.org/https://doi.org/10.1037/a0026396

Lynch, K. (1960). The image of the city. MIT Press.

Macdonald, S. (2007). Interconnecting: museum visiting and exhibition design. CoDesign, 3(S1), 149-162. https://doi.org/10.1080/15710880701311502

MacLeod, S., Austin, T., Hale, J., \& Hing-Kay, O. H. (2018). The Future of Museum and Gallery Design. Routledge.

Mayr, E., Knipfer, K., \& Wessel, D. (2009). In-sights into mobile learning: An exploration of mobile eye tracking methodology for learning in museums. In G. Vavoula, N. Pachler, \& A. Kukulska-Hulme (Eds.), Researching mobile learning: Frameworks, tools and research designs (pp. 189-204). Peter Lang.

Melton, A. W. (1935). Problems of installation in museums of art (New Series). American Association of Museums.

Merton, R. K., \& Kendall, P. L. (1946). The Focused Interview. American Journal of Sociology, 51(6), 541-557.

Milekic, S. (2010). Gaze-Tracking and Museums: Current Research and Implications. In J. Trant \& D.
Bearman (Eds.), Museums and the Web 2010: Proceedings. Archives \& Museum Informatics. http://www.archimuse.com/mw2010/papers/milekic /milekic.html

Müller, A. M., \& Möhlmann, F. (2014). New Exhibition Design 1900-2000. avedition.

Niehorster, D. C., Santini, T., Hessels, R. S., Hooge, I. T. C., Kasneci, E., \& Nyström, M. (2020). The impact of slippage on the data quality of head-worn eye trackers. Behavior Research Methods, 1-21. https://doi.org/10.3758/s13428-019-01307-0

Noordegraaf, J. (2004). Strategies of Display. Museum Presentation in Nineteenth- and Twentieth-Century Visual Culture. Museum Boijmans Van Beuningen / NAi Publishers.

Pekarik, A. J., Doering, Z. D., \& Karns, D. A. (1999). Exploring Satisfying Experiences in Museums. Curator: The Museum Journal, 42(2), 152-173. https://doi.org/10.1111/j.21516952.1999.tb01137.x

Pekarik, A. J., \& Schreiber, J. B. (2012). The Power of Expectation. Curator: The Museum Journal, 55(4), 487-496. https://doi.org/10.4103/heartviews.heartviews_38 17

Pelowski, M., Forster, M., Tinio, P., Scholl, M., \& Leder, H. (2017). Beyond the Lab: An Examination of Key Factors Influencing Interaction with 'Real' and Museum-based Art. Psychology of Aesthetics Creativity and the Arts, 11(3), 245-264. https://doi.org/10.1037/aca0000141

Pelowski, M., Leder, H., Mitschke, V., Specker, E., Gerger, G., Tinio, P. P. L., Vaporova, E., Bieg, T., \& Husslein-Arco, A. (2018). Capturing aesthetic experiences with installation art: An empirical assessment of emotion, evaluations, and mobile eye tracking in Olafur Eliasson's "Baroque, Baroque!" Frontiers in Psychology, 9(AUG). https://doi.org/10.3389/fpsyg.2018.01255

Pelowski, M., Markey, P. S., Forster, M., Gerger, G., \& Leder, H. (2017). Move me, astonish me... Delight my eyes and brain: The Vienna Integrated Model of top-down and bottom-up processes in Art Perception (VIMAP) and corresponding affective, evaluative, and neurophysiological correlates. Physics of Life Reviews, 21, 80-125. https://doi.org/10.1016/j.plrev.2017.02.003 
Pelowski, M., Markey, P. S., Lauring, J. O., \& Leder, H. (2016). Visualizing the Impact of Art: An Update and Comparison of Current Psychological Models of Art Experience. Frontiers in Human Neuroscience, 10(Article 160). https://doi.org/10.3389/fnhum.2016.00160

Pihko, E., Virtanen, A., Saarinen, V.-M., Pannasch, S., Hirvenkari, L., Tossavainen, T., Haapala, A., \& Hari, R. (2011). Experiencing Art: The Influence of Expertise and Painting Abstraction Level. Frontiers in Human Neuroscience, 5, 94. https://doi.org/10.3389/fnhum.2011.00094

Porter, M. (1938). Behavior of the average visitor in the Peabody Museum of Natural History Yale University (New Series). American Association of Museums.

Quiroga, R. Q., Dudley, S., \& Binnie, J. (2011). Looking at Ophelia: A comparison of viewing art in the gallery and in the lab. $A C N R, 11(3), 15-18$.

Reitstätter, L. (2015). Die Ausstellung verhandeln: Von Interaktionen im musealen Raum. transcript.

Robinson, E. S. (1928). The Behaviour of the Museums Visitor (New Series). American Association of Museums.

Rosenberg, R. (2014). Blicke messen: Vorschläge für eine empirische Bildwissenschaft. In Bayerische Akademie der Schönen Künste. Jahrbuch 27. 2013 (pp. 71-86). Wallstein.

Rosenberg, R., \& Klein, C. (2015). The moving eye of the beholder: Eye tracking and the perception of paintings. In J. P. Huston, M. Nadal, F. Mora, L. F. Agnati, \& C. J. Cela-Conde (Eds.), Art, Aesthetics, and the Brain (pp. 79-110). Oxford University Press.

Russell, P. A. (2003). Effort after meaning and the hedonic value of paintings. British Journal of Psychology, 94(1), 99-110. https://doi.org/10.1348/000712603762842138

Sancarlo, R., Dare, Z., Arato, J., \& Rosenberg, R. (2020). Investigating the relationship between gaze path and pictorial composition within four centuries of the Last Supper. Journal of Eye Movement Research, 13(2), Manuscript submitted for publication.

Santini, T., Brinkmann, H., Reitstätter, L., Leder, H., Rosenberg, R., Rosenstiel, W., \& Kasneci, E. (2018). The Art of Pervasive Eye Tracking. In 7th
Workshop on Pervasive Eye Tracking and Mobile Eye-Based Interaction - PETMEI 2018 (p. Article 5). https://doi.org/10.1145/3208031.3208032

Santini, T., Fuhl, W., Geisler, D., \& Kasneci, E. (2017). EyeRecToo: Open-Source Software for Real-Time Pervasive Head-Mounted Eye-Tracking. Proceedings of VISIGRAPP 2017.

Santini, T., Fuhl, W., \& Kasneci, E. (2018a). PuRe: Robust pupil detection for real-time pervasive eye tracking. Computer Vision and Image Understanding, 170, 40-50. https://doi.org/10.1016/j.cviu.2018.02.002

Santini, T., Fuhl, W., \& Kasneci, E. (2017). CalibMe: Fast and unsupervised eye tracker calibration for gazebased pervasive human-computer interaction. Proceedings of CHI, 2594-2605.

Santini, T., Fuhl, W., \& Kasneci, E. (2018b). PuReST: Robust pupil tracking for real-time pervasive eye tracking. Eye Tracking Research and Applications Symposium (ETRA), 1-5. https://doi.org/10.1145/3204493.3204578

Santini, T., Niehorster, D. C., \& Kasneci, E. (2019). Get a grip: Slippage-robust and glint-free gaze estimation for real-time pervasive head-mounted eye tracking. Eye Tracking Research and Applications Symposium (ETRA). https://doi.org/10.1145/3314111.3319835

Serrell, B. (1998). Paying Attention: Visitors and Museum Exhibitions. American Association of Museums Press.

Serrell, B. (2010). Paying More Attention to Paying Attention. Informal Science: Learning Sciences. https://www.informalscience.org/sites/default/files/ S\&A.PA2.FinalDforCAISE2016.pdf

Serrell, B. (2015). Exhibit Labels: An Interpretive Approach. Rowman and Littlefield.

Skov, M., Lykke, M., \& Jantzen, C. (2018). Introducing Walk-Alongs in Visitor Studies: A Mobile Method Approach to Studying User Experience. Visitor Studies, 21(2), 189-210. https://doi.org/10.1080/10645578.2018.1549396

Smith, J. K., \& Smith, L. F. (2001). Spending Time on Art. Empirical Studies of the Arts, 19(2), 229-236. https://doi.org/10.2190/5mqm-59jh-x21r-jn5j

Smith, L. F., Smith, J. K., \& Tinio, P. P. L. (2017). Time Spent Viewing Art and Reading Labels. Psychology 
of Aesthetics, Creativity, and the Arts, 11(1), 77-85. https://doi.org/10.1037/aca0000049

Specker, E., Forster, M., Brinkmann, H., Boddy, J., Pelowski, M., Rosenberg, R., \& Leder, H. (2018). The Vienna Art Interest and Art Knowledge Questionnaire (VAIAK): A Unified and Validated Measure of Art Interest and Art Knowledge. Psychology of Aesthetics, Creativity, and the Arts. https://doi.org/https://doi.org/10.1037/aca0000205

Specker, E., Tinio, P. P. L., \& Van Elk, M. (2017). Do You See What I See? An Investigation of the Aesthetic Experience in the Laboratory and Museum. Psychology of Aesthetics, Creativity, and the Arts, 11, 265-275. https://doi.org/10.1037/aca0000107

Staniszewski, M. A. (1998). The power of display. A history of exhibition installations at the Museum of Modern Art. MIT Press.

Steier, R., Pierroux, P., \& Krange, I. (2015). Embodied interpretation: Gesture, social interaction, and meaning making in a national art museum. Learning, Culture and Social Interaction, 7(December 2015), 28-42. https://doi.org/10.1016/j.lcsi.2015.05.002

Treu, G. (1900). Max Klinger als Bildhauer [Sonderdruck aus der Zeitschrift Pan]. E. A. Seemann.

Tröndle, M., Greenwood, S., Bitterli, K., \& van den Berg, K. (2014). The effects of curatorial arrangements. Museum Management and Curatorship, 29(2), 140173. https://doi.org/10.1080/09647775.2014.888820

Wagner, C. (2013). Der Mythos vom "unschuldigen Auge": Blickbewegungen, Wahrnehmungsprozesse in der Bildenden Kunst. In C. Wagner, M. W. Greenlee, \& C. Wolff (Eds.), Aisthesis. Wahrnehmungsprozesse und Visualisierungsformen in Kunst und Technik (pp. 31-50). Schnell \& Steiner.
Wagner, C. (2016). Mapping the Eye: Laocoön and Eye Movement in Art. In M. Zimmermann (Ed.), Vision in Motion. Streams of Sensation and Configurations of Time (pp. 201-219). Diaphanes.

Walker, F., Bucker, B., Anderson, N. C., Schreij, D., \& Theeuwes, J. (2017). Looking at paintings in the Vincent Van Gogh Museum: Eye movement patterns of children and adults. PLoS ONE, 12(6), e0178912.

https://doi.org/10.1371/journal.pone.0178912

Ward, M. (1991). Impressionist Installations and Private Exhibitions. The Art Bulletin, 73(4), 599-622. https://doi.org/10.2307/3045832

Wiseman, B., Carusi, A., Briggs, E., Poyntz, S., Pelowski, M., Alcock, L., \& Mazzà, C. (2019). Embodied viewing and Degas's Little Dancer Aged Fourteen: A multi-disciplinary experiment in eye-tracking and motion capture. The Senses and Society, 14(3), 284 296. https://doi.org/10.1080/17458927.2019.1652413

Yalowitz, S. S., \& Bronnenkant, K. (2009). Timing and tracking: Unlocking visitor behavior. Visitor Studies, 12(1), 47-64. https://doi.org/10.1080/10645570902769134

Yarbus, A. L. (1967). Eye Movements and Vision. Plenum Press. 
Journal of Eye Movement Research

13(2):6

\section{Appendix}

Table A1. List of artworks in BB (in hanging order)

\begin{tabular}{|c|c|c|c|}
\hline \multicolumn{4}{|l|}{ Belvedere Before } \\
\hline Artist & Title & Abbreviated title & Year \\
\hline Bernatzik, Wilhelm & Pond & Pond & c. 1900 \\
\hline Khnopff, Fernand & Calm Water (The Pond of Menil) & Calm Water & 1896 \\
\hline Moll, Carl & Twilight & Twilight & 1900 \\
\hline Gallén-Kallela, Akseli & Early Spring & Early Spring & c. 1900 \\
\hline Segantini, Giovanni & The Evil Mothers & Evil Mothers & 1894 \\
\hline Orlik, Emil & Dachstein & Dachstein & 1904 \\
\hline Moser, Koloman & Self-Portrait & Self-Portrait & 1890 \\
\hline Van Gogh, Vincent & The Plain of Auvers & Plain Auvers & 1890 \\
\hline Munch, Edvard & The Painter Paul Herrmann and the Physician Paul Contard & Painter Physician & 1897 \\
\hline Rodin, Auguste & Eve & Eve & 1881 \\
\hline Schindler, Emil Jakob & Pax & Pax & 1891 \\
\hline Klinger, Max & The Judgement of Paris & Judgement & $1885-1887$ \\
\hline Böcklin, Arnold & Sea Idyll & Sea Idyll & 1887 \\
\hline Von Hofman, Ludwig & Largo (Sunset) & Largo & c. 1898 \\
\hline Khnopff, Fernand & Half-figure of a Nymph (“Vivien”) & Nymph & 1896 \\
\hline Klinger, Max & Crouching Woman & Crouching Woman & $1900-1901$ \\
\hline Klimt, Gustav & Amalie Zuckerkandl & Amalie Zuckerkandl & $1917 / 1918$ \\
\hline Klimt, Gustav & The Bride & Bride & $1917 / 1918$ \\
\hline Klimt, Gustav & Fritza Riedler & Fritza Riedler & 1906 \\
\hline Klimt, Gustav & Judith & Judith & 1901 \\
\hline Klimt, Gustav & Josef Lewinsky as Carlos in Clavigo & Josef Lewinsky & 1895 \\
\hline Klimt, Gustav & Lady in White & Lady White & $1917 / 1918$ \\
\hline Klimt, Gustav & Girlfriends (Water Serpents I) & Girlfriends & 1904 \\
\hline Klimt, Gustav & Lady at the Fireplace & Lady Fireplace & $1897 / 1898$ \\
\hline Klimt, Gustav & Draft for the Allegory of Music (The organ player) & Allegory Music & 1885 \\
\hline Klimt, Gustav & The Kiss (Lovers) & Kiss & $1908 / 1909$ \\
\hline
\end{tabular}


Table A2. List of artworks in BA (in hanging order)

\begin{tabular}{|c|c|c|c|}
\hline \multicolumn{4}{|l|}{ Belvedere After } \\
\hline Artist & Title & Abbreviated title & Year \\
\hline Makart, Hans & Dante and Vergil in Hell & Dante Vergil & $1863 / 1865$ \\
\hline Makart, Hans & Antique Sacrifice & Antique Sacrifice & c. 1880 \\
\hline Feuerbach, Anselm & Orpheus and Eurydice & Orpheus Eurydice & $1868-1869$ \\
\hline Böcklin, Arnold & Sea Idyll & Sea Idyll & 1887 \\
\hline Klimt, Gustav & Josef Lewinsky as Carlos in Clavigo & Josef Lewinsky & 1895 \\
\hline Klimt, Gustav & Marie Kerner von Marilaun as a Bride & Marie Kerner & $1891-1892$ \\
\hline Klimt, Gustav & Portrait of a Lady in Black & Lady Black & c. 1894 \\
\hline Klinger, Max & Crouching Woman & Crouching Woman & $1900-1901$ \\
\hline Friedl, Theodor & Cupid and Psyche & Cupid Psyche & c. 1890 \\
\hline Bernatzik, Wilhelm & Pond & Pond & c. 1900 \\
\hline Moll, Carl & Twilight & Twilight & 1900 \\
\hline Hölzel, Adolf & White Poplars & White Poplars & 1900 \\
\hline Munch, Edvard & Men on the Seashore & Seashore & 1908 \\
\hline Van Gogh, Vincent & The Plain of Auvers & Plain Auvers & 1890 \\
\hline Hodler, Ferdinand & Emotion & Emotion & 1900 \\
\hline Segantini, Giovanni & The Evil Mothers & Evil Mothers & 1894 \\
\hline Gallén-Kallela, Akseli & Early Spring & Early Spring & c. 1900 \\
\hline Von Stuck, Franz & Lost & Lost & 1891 \\
\hline Minne, Georg & Woman Bathing & Woman Bathing & Undated \\
\hline Klimt, Gustav & Judith & Judith & 1901 \\
\hline Khnopff, Fernand & Half-figure of a Nymph ("Vivien") & Nymph & 1896 \\
\hline Jaschke, Franz & Donaulände in Summer & Donaulände Summer & 1903 \\
\hline Kurzweil, Max & Portrait of Therese Bloch-Bauer & Therese Bloch-Bauer & um 1907 \\
\hline Rodin, Auguste & Gustav Mahler & Gustav Mahler & 1909 \\
\hline Klinger, Max & Beethoven & Beethoven & 1907 \\
\hline Klimt, Gustav & Schloss Kammer on Lake Attersee III & Schloss Kammer & $1909 / 1910$ \\
\hline Klimt, Gustav & Sonja Knips & Sonja Knips & $1897 / 1898$ \\
\hline Klimt, Gustav & Fritza Riedler & Fritza Riedler & 1906 \\
\hline Gerstl, Richard & The Sisters Karoline and Pauline Fey & Sisters Fey & 1905 \\
\hline Kokoschka, Oskar & The Visitation & Visitation & 1912 \\
\hline Klimt, Gustav & Forester's House in Weissenbach on the Attersee I & Forester's House & 1914 \\
\hline Klimt, Gustav & The Kiss (Lovers) & Kiss & $1908 / 1909$ \\
\hline Klimt, Gustav & Flowering Poppies & Flowering Poppies & 1907 \\
\hline Rodin, Auguste & Eve & Eve & 1881 \\
\hline Klimt, Gustav & Cottage Garden with Sunflowers & Cottage Garden & 1907 \\
\hline
\end{tabular}


Table A3. Viewing times in seconds for 13 artworks and labels in BB

\begin{tabular}{lllll}
\hline $\mathrm{N}^{\circ}$ & Belvedere Before & Artwork & Label & Artwork \& Label \\
\hline & Abbreviated title & Mean $(S D)$ & Mean $(S D)$ & Mean $(S D)$ \\
\hline 1 & Kiss & $56.94(38.57)$ & $1.70(3.33)$ & $58.64(38.71)$ \\
2 & Judith & $24.44(21.68)$ & $1.69(2.04)$ & $26.13(21.90)$ \\
3 & Fritza Riedler & $23.86(16.16)$ & $2.20(3.13)$ & $26.06(16.66)$ \\
4 & Evil Mothers & $21.03(18.66)$ & $2.41(3.01)$ & $23.44(19.94)$ \\
5 & Sea Idyll & $15.66(12.81)$ & $1.93(2.44)$ & $17.59(13.71)$ \\
6 & Josef Lewinsky & $13.26(11.45)$ & $3.05(2.82)$ & $16.31(11.97)$ \\
7 & Plain Auvers & $13.15(12.69)$ & $2.77(3.67)$ & $15.91(14.21)$ \\
8 & Early Spring & $8.70(8.78)$ & $2.47(3.26)$ & $11.17(10.62)$ \\
9 & Pond & $7.34(5.81)$ & $2.00(2.94)$ & $9.35(6.72)$ \\
10 & Nymph & $6.65(7.87)$ & $0.70(2.01)$ & $7.35(8.76)$ \\
11 & Crouching Woman & $6.27(12.69)$ & $0.14(0.60)$ & $6.41(12.65)$ \\
12 & Twilight & $5.38(6.05)$ & $1.67(2.20)$ & $7.05(7.19)$ \\
13 & Eve & $5.09(6.78)$ & $0.00(0.00)$ & $5.09(6.78)$ \\
& Total & $15.98(21.07)$ & $1.89(2.76)$ & $17.73(21.65)$ \\
\hline
\end{tabular}

Table A4. Viewing times in seconds for 13 artworks and labels in BA

\begin{tabular}{lllll}
\hline $\mathrm{N}^{\circ}$ & Belvedere After & Artwork & Label & Artwork \& Label \\
\hline & Abbreviated title & Mean $(S D)$ & Mean $(S D)$ & Mean $(S D)$ \\
\hline 1 & Kiss & $57.92(48.54)$ & $14.09(21.61)$ & $72.01(57.84)$ \\
2 & Evil Mothers & $30.58(33.39)$ & $4.75(5.01)$ & $35.34(35.78)$ \\
3 & Judith & $30.30(31.02)$ & $16.51(17.51)$ & $46.80(39.97)$ \\
4 & Fritza Riedler & $27.60(27.80)$ & $3.21(3.65)$ & $30.81(28.95)$ \\
5 & Sea Idyll & $21.31(16.60)$ & $3.83(5.71)$ & $25.13(18.76)$ \\
6 & Josef Lewinsky & $18.15(24.05)$ & $14.74(18.27)$ & $32.89(38.58)$ \\
7 & Plain Auvers & $15.84(18.02)$ & $13.50(16.33)$ & $29.35(29.64)$ \\
8 & Nymph & $11.53(18.16)$ & $3.35(4.17)$ & $14.87(21.67)$ \\
9 & Pond & $11.01(21.71)$ & $3.18(3.85)$ & $14.19(23.97)$ \\
10 & Early Spring & $9.47(9.40)$ & $2.67(2.61)$ & $12.14(10.78)$ \\
11 & Twilight & $8.86(10.89)$ & $2.64(3.23)$ & $11.50(12.84)$ \\
12 & Eve & $7.40(13.73)$ & $1.48(2.02)$ & $8.88(14.55)$ \\
13 & Crouching Woman & $4.19(6.85)$ & $1.77(3.05)$ & $5.96(9.22)$ \\
& Total & $19.55(27.77)$ & $6.59(12.01)$ & $26.14(34.28)$ \\
\hline
\end{tabular}


Figure A1. Questionnaire

\section{A Artworks (seen before and highlight)}

A_01 Which art work(s) have you already seen before your visit of today (as original or reproduction)? multiple choice among all artworks presented in the three rooms

A_02 Which of these artworks has been your personal highlight? single choice among all artworks presented in the rooms

\section{B Exhibition experience (in relation to display issues)}

B_01 Our study deals with different aspects that might influence the art perception in a museum. In the following we would like to kindly ask you to share your personal art experience in the last three exhibition rooms with us. There are no right or wrong answers. Please indicate how much you agree with the following statements:

\begin{tabular}{|c|c|c|c|c|c|c|c|}
\hline & $\begin{array}{l}\text { Not at } \\
\text { all (1) }\end{array}$ & $(2)$ & (3) & (4) & $(5)$ & $(6)$ & $\begin{array}{c}\text { Very } \\
\operatorname{much}(7)\end{array}$ \\
\hline $\begin{array}{l}\text { I was mainly interested in the paintings } \\
\text { (1) }\end{array}$ & $\mathrm{O}$ & $\mathrm{O}$ & $\mathrm{O}$ & $\mathrm{O}$ & $\mathrm{O}$ & O & O \\
\hline $\begin{array}{l}\text { I was mainly interested in the sculp- } \\
\text { tures (2) }\end{array}$ & $\mathrm{O}$ & O & O & $\mathrm{O}$ & O & $\mathrm{O}$ & O \\
\hline I focused on single artworks (3) & O & O & O & O & O & O & O \\
\hline $\begin{array}{l}\text { I focused on the relationships between } \\
\text { the artworks (4) }\end{array}$ & 0 & 0 & $\mathrm{O}$ & 0 & 0 & 0 & 0 \\
\hline $\begin{array}{l}\text { I was mainly interested in the artworks } \\
\text { by Gustav Klimt (5) }\end{array}$ & $\mathrm{O}$ & O & O & $\mathrm{O}$ & $\mathrm{O}$ & $\mathrm{O}$ & O \\
\hline $\begin{array}{l}\text { I would have liked to have more textual } \\
\text { information (6) }\end{array}$ & $\mathrm{O}$ & $\mathrm{O}$ & O & $\mathrm{O}$ & O & $\mathrm{O}$ & O \\
\hline $\begin{array}{l}\text { I could read the labels on the wall very } \\
\text { well. (7) }\end{array}$ & $\mathrm{O}$ & $\mathrm{O}$ & O & O & O & O & O \\
\hline $\begin{array}{c}\text { When viewing the artworks I felt im- } \\
\text { paired by other visitors ( } 8 \text { ) }\end{array}$ & O & $\mathrm{O}$ & O & $\mathrm{O}$ & $\mathrm{O}$ & $\mathrm{O}$ & O \\
\hline $\begin{array}{l}\text { The lightning situation in the exhibition } \\
\text { rooms was pleasing (9) }\end{array}$ & $\mathrm{O}$ & O & O & O & $\mathrm{O}$ & 0 & 0 \\
\hline $\begin{array}{l}\text { The colors of the walls in the exhibition } \\
\text { rooms were pleasing (10) }\end{array}$ & 0 & 0 & 0 & 0 & 0 & 0 & 0 \\
\hline $\begin{array}{l}\text { Overall, I felt comfortable in the exhi- } \\
\text { bition rooms (11) }\end{array}$ & 0 & 0 & 0 & 0 & 0 & 0 & 0 \\
\hline
\end{tabular}




\section{Personal art interest}

C_01 Please indicate how much you agree with the following statements:

\begin{tabular}{|c|c|c|c|c|c|c|c|}
\hline & $\begin{array}{l}\text { Not at } \\
\text { all (1) }\end{array}$ & $(2)$ & (3) & (4) & $(5)$ & (6) & $\begin{array}{c}\text { Very } \\
\text { much (7) }\end{array}$ \\
\hline $\begin{array}{c}\text { I enjoyed visiting art class in } \\
\text { school (1) }\end{array}$ & 0 & 0 & 0 & 0 & 0 & 0 & 0 \\
\hline $\begin{array}{c}\text { I enjoy talking about art with } \\
\text { others (2) }\end{array}$ & O & O & $\mathrm{O}$ & O & O & O & O \\
\hline $\begin{array}{l}\text { I have many friends/acquaint- } \\
\text { ances who are interested in art } \\
\text { (3) }\end{array}$ & $\bigcirc$ & O & O & O & O & $\mathrm{O}$ & O \\
\hline I am interested in art (4) & O & O & O & O & 0 & $\mathrm{O}$ & $\mathrm{O}$ \\
\hline $\begin{array}{c}\text { I am always looking for new ar- } \\
\text { tistic impressions and experi- } \\
\text { ences (5) }\end{array}$ & O & O & $\mathrm{O}$ & $\mathrm{O}$ & O & $\mathrm{O}$ & O \\
\hline $\begin{array}{c}\text { During my everyday life I } \\
\text { spontaneously notice art objects } \\
\text { that I find fascinating }(6)\end{array}$ & O & O & O & O & O & $\mathrm{O}$ & O \\
\hline $\begin{array}{c}\text { I come from a family that is in- } \\
\text { terested in art (7) }\end{array}$ & $\mathrm{O}$ & O & O & O & O & $\mathrm{O}$ & O \\
\hline
\end{tabular}

C_02 Please indicate the most adequate answer to the four following questions:

$\begin{array}{lcccccc}\text { less than } & \text { once per } & \text { once per } & \begin{array}{c}\text { once } \\ \text { every }\end{array} & \text { once per } & \text { once } & \text { once per } \\ \text { ence per } & \text { half-year } & \text { three } & \text { week or } \\ \text { year (1) } & \text { year (2) } & (3) & \begin{array}{c}\text { months } \\ \text { month (5) }\end{array} & \begin{array}{c}\text { fortnight } \\ \text { more of- }\end{array} \\ & & & (4) & & (6) & \text { ten (7) }\end{array}$

How often do you visit art museums or art galleries on aver-

$$
\text { age? (1) }
$$

How often do you read books, magazines or catalogues about art? (2)

How often do you view images of artworks (picture books, internet, etc.)? (3)

How often do you visit events about art or art history? (4)

$\bigcirc$

O

○

O

O

O

O 


\section{Museum visit}

Now we would like you to share some information about today's museum visit with us:

D_01 How have you visited the museum today?

○ On my own (1)

○ In company (2)

D 011 With how many people (excluding you) have you visited the museum today? Persons (1)

D_01_2 How would you describe this group?
○ Family (1)
Friends (2)
C Colleagues (3)
Travel group (4)
O Other (5)

D 02 How many times have you been to the Belvedere?

O Today for the first time (1)

- 2-5 times (2)

○ More often (3)

D_03 Was your visit part of a trip?

○ Yes (1)

O No (2)

D_03_1 If yes, please specify your "trip":

O Excursion/domestic trip (1)

O Holiday (2)

○ Business trip (3)

O Other (4)

D_04 How likely would you recommend the Belvedere to a friend or colleague?

○ Highly likely (1)

○ Most likely (2)

F Fairly likely (3)

○ Not so likely (4)

○ Not at all likely (5)

\section{E Mobile eye tracking}

Now we would like you to answer some questions on the eye tracking:

E_01 At a certain point in time I forgot the eye tracking glasses.

○ Immediately (1)

O After 1-2 minutes (2)

O After 3-5 minutes (3)

○ After 6-10 minutes (4)

○ Never (5) 
E_02 Please indicate how much you agree with the following statements:

\begin{tabular}{lccccccc}
\hline & $\begin{array}{c}\text { Not at all } \\
(1)\end{array}$ & (2) & (3) & (4) & (5) & (6) & $\begin{array}{c}\text { Very } \\
\text { much (7) }\end{array}$ \\
\hline $\begin{array}{c}\text { The instructions for the calibrations } \\
\text { were easy to follow (1) }\end{array}$ & 0 & 0 & 0 & 0 & 0 & 0 & 0 \\
$\begin{array}{c}\text { I have perceived the eye tracking } \\
\text { glasses as comfortable (2) }\end{array}$ & 0 & 0 & 0 & 0 & 0 & 0 & 0 \\
$\begin{array}{c}\text { The eye tracking glasses have limited } \\
\text { my sight (3) }\end{array}$ & 0 & 0 & 0 & 0 & 0 & 0 & 0 \\
$\begin{array}{c}\text { I have found the backpack uncomforta- } \\
\text { ble (4) }\end{array}$ & 0 & 0 & 0 & 0 & 0 & 0 & 0 \\
$\begin{array}{l}\text { I felt observed during my visit with the } \\
\text { eye tracking glasses (5) }\end{array}$ & 0 & 0 & 0 & 0 & 0 & 0 & 0 \\
$\begin{array}{c}\text { My art perception has changed because } \\
\text { of the eye tracking equipment (6) }\end{array}$ & 0 & 0 & 0 & 0 & 0 & 0 & 0 \\
\hline
\end{tabular}

\section{F Demographics}

Finally we would like to ask you to share some information on your person:

$$
\begin{array}{cl}
\text { F_01 Sex } \\
\text { O } & \text { Male (1) } \\
\text { O } & \text { Female (2) } \\
\text { O } & *(3)
\end{array}
$$

F_02 Personal data

Age:

Place of residence:

Nationality:

Born and raised in (country):

Native language:

Other fluently spoken languages:

F_03 Highest completed level of education

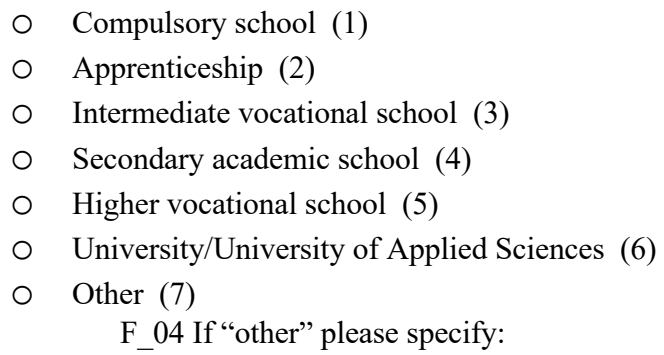

Thank you very much for participating in this study! If you have any questions, please just ask the team. 